Research Article

\title{
Evaluating the Impact of Blast-Induced Damage on the Rock Load Supported by Liner in Construction of a Deep Shaft: A Case Study of Ventilation Shaft of Micangshan Road Tunnel Project
}

\author{
Yong Fang $\mathbb{D}^{1},{ }^{1}$ Zhigang Yao ${ }^{D},{ }^{1}$ Gabriel Walton, ${ }^{2}$ Jian Zhou, ${ }^{1}$ Wanghao Xu, \\ and Yuchao Zheng $\mathbb{D}^{1}$ \\ ${ }^{1}$ Key Laboratory of Transportation Tunnel Engineering of Ministry of Education, Southwest Jiaotong Univ., \\ 610031 Chengdu, China \\ ${ }^{2}$ Department of Geology and Geological Engineering, Colorado School of Mines, Golden, CO, USA
}

Correspondence should be addressed to Yuchao Zheng; yczh@swjtu.edu.cn

Received 29 August 2019; Revised 23 December 2019; Accepted 3 January 2020; Published 29 January 2020

Academic Editor: Flavio Stochino

Copyright (c) 2020 Yong Fang et al. This is an open access article distributed under the Creative Commons Attribution License, which permits unrestricted use, distribution, and reproduction in any medium, provided the original work is properly cited.

The rock load acting on the lining of an underground excavation is influenced by multiple factors, including rock type, rock mass condition, depth, and construction method. This study focuses on quantifying the magnitude and distribution of the radial loads on the lining of a deep shaft constructed in hard rock by the so-called short-step method. The blasting-induced damage zone (BDZ) around the shaft was characterized using ultrasonic testing and incorporated into the convergence-confinement method (CCM) and 3D numerical analyses to assess the impact of $\mathrm{BDZ}$ on rock loading against the liner. The results show that excavation blasting of shafts is an important controlling factor for the degradation of the rock mass, while the orientation and magnitude of the principal stress had a minimal influence on the distribution of blast-induced damage. The analysis shows that increasing the depth of blast damage in the walls can increase the loads acting on the lining, and the shear loads acting on the liner could be significant for shafts sunk by the short-step method in an area with anisotropic in situ stresses.

\section{Introduction}

Vertical ventilation shafts are passages widely used in mines and tunnels to provide fresh air underground and to remove exhaust or smoke in case of a fire [1-4]. In some extralong tunnels constructed in China, such as highway tunnels in Nibashan $(10 \mathrm{~km})$, Mi Cangshan $(13.8 \mathrm{~km})$, and Zhong Nanshan $(18 \mathrm{~km})$, vertical ventilation shafts were set in the middles of the alignments. These vertical shafts, extending hundreds of meters deep, are often constructed in mountainous terrain; such shafts and shafts constructed in soft ground differ greatly with respect to the construction method and lining design.

The lining of a vertical shaft in soft ground can be designed similarly to a retaining structure $[5,6]$. The lateral Earth pressure acting on a retaining wall is well understood and has been previously studied by many researchers [7-9]. Theoretical methods such as the limit equilibrium [10] and the slip line methods [11] were developed to analyze the lateral pressure on circular shaft liners. For shallow shafts, when the maximum depth is not much greater than the diameter, analytical solutions can provide approximate estimates of the lateral Earth pressure on the lining. As the depth of the shaft exceeds its diameter, the lateral Earth pressure becomes increasingly sensitive to the radial soil displacement. Many experimental tests revealed the phenomenon that the lateral pressure on the shaft lining decreases with increasing radial soil displacement during excavation [12-15]. Experimental tests and field tests carried out by Kim et al. [16] and Cho et al. [17] show that the lateral Earth pressure acting on a vertical circular shaft does not increase linearly as a function of depth. The lateral Earth pressure values they observed are about 80\% smaller than those calculated by Rankine theory, considering the arching effect. Therefore, analytical solutions for shaft liner loading are limited in their range of applicability, and the relationship between the radial soil displacement and the liner loading needs to be further investigated [18]. 
The construction and design of a vertical deep shaft in rock is complicated. The convergence confinement method (CCM), which is widely applied to tunnels [19-23], was introduced by Wong and Kaiser [24] to estimate the radial ground displacements and the loads on a vertical shaft. As the shaft excavation advances and the shaft bottom moves close to the section under consideration, the radial ground displacement increases and the effective support pressure (associated with three-dimensional face advance effects) decreases. If ground support such as a liner is installed after a given amount of ground displacement has occurred $\left(u_{\mathrm{r} 0}\right)$, it will begin to take on the load because the ground continues to deform until an equilibrium is reached. This is represented by the intersection of the convergence-confinement curve and the support reaction line, as shown in Figure 1. Accordingly, the effective support pressure provided by the shaft lining (equivalent to the ground load on the lining) can be calculated by the CCM. Taking the intersection between the convergence-confinement curve (CCC) and the reaction line of the support into account, Spagnoli et al. [25] proposed new equations for estimation of radial loads on the shaft lining. Combining the CCM and numerical analysis, Spagnoli et al. [26] investigated the relationship between the radial loads acting on liner support and the radial displacement of the ground for vertical circular shaft sinking in weak rocks, and they concluded that the lining thickness would affect the radial loads and radial ground displacement.

The ground displacement around a deep shaft in highly stressed ground largely depends on the mechanical properties of the rock mass [27]. Many studies have shown that the behavior of the rock mass close to the shaft lining is often inelastic in nature and is influenced by preexisting structural weaknesses. van de Steen et al. [28] studied the fracturing around a deep shaft using a flawed model and found that the fracturing was affected by the horizontal stresses. Renani et al. [29] used an elastoplastic constitutive model to back analyze the radial ground displacement based on the data collected by multipoint extensometers installed around a deep shaft. The results showed that the effective strength and stiffness of the rock mass were much lower than expected for the intact rock. In addition to the influence of preexisting structural weaknesses, the rock damage induced by the blasting has also great influence on the surrounding rock mass stability and the in situ stress redistribution around a deep tunnel [30], and accordingly, blast-induced rock damage should be taken into consideration in the analysis of rock mass behavior around a deep shaft.

Many publications have shown that blast-induced rock damage affects the rock mass behavior around a tunnel excavated using a drill and blast method [31-34]. Yilmaz and Unlu [35] and Yang et al. [36] studied the dimensions of rock mass damage zones induced by blasting using numerical methods. Verma et al. [37] carried out field investigations at different tunnels to study blast-induced damage for a wide range of rock mass qualities. Previous studies investigating the loads acting on shaft linings consider the displacement and stress distribution around the shaft, but the impact of the blast-induced damage is not taken into account [38-40]. In this article, field tests on the blast-induced damage distribution around a deep shaft were carried out. Considering the blast-induced damage, the radial ground movement associated with the excavation of the shaft was estimated using a numerical model, and the radial loads on the shaft lining, which were compared with the numerical model results, were estimated using the CCM.

\section{Case Study Project Description}

The Micangshan twin highway tunnels $(13.8 \mathrm{~km})$ connecting the Sichuan Province to the Shaanxi Province are in the western part of China, as shown in Figure 2. A vertical circular shaft with $9.0 \mathrm{~m}$ diameter was placed in the middle of Mi Cangshan tunnels for ventilation purposes during future operation of the tunnel.

The shaft is currently being excavated to a final depth of more than $400 \mathrm{~m}$ beneath the ground surface. Generally, the excavation and lining design for a vertical shaft at this depth relies heavily on empirical methods that consider the mechanical properties of the rock masses along the shaft alignment. Exploratory boreholes showed that the rock formation along the length of the shaft is mainly composed of quartz diorite. Laboratory tests on the mechanical properties of the quartz diorite unit were carried out, including uniaxial compression tests and triaxial compression tests. The intact rock parameters evaluated include the uniaxial compressive strength, UCS, tensile strength, $\sigma_{\mathrm{t}}$, Young's modulus, $E$, and Poisson's ratio, $v$, from the uniaxial tests, the Hoek-Brown parameter, $m_{i}$, the tensile strength, $\sigma_{t}$, from the Brazilian tests, and seismic velocity, $V_{\mathrm{p}}$, from the ultrasonic tests; these parameter values are summarized in Table 1.

Hydraulic fracturing and overcoring were used to constrain the in situ stress field; the results of the stress measurement campaign are summarized in Figure 3. It was found that the orientation of the major in situ principal stress is between $\mathrm{N} 26^{\circ} \mathrm{W}$ and $\mathrm{N} 35^{\circ} \mathrm{W}$ in the horizontal plane.

The shaft was excavated using short rounds of full-face drilling and blasting, which is an approach that is widely used for shaft sinking [41]. The advance length in each excavation round was set to $4.0 \mathrm{~m}$, and each excavation cycle took about 24 hours. The sequence for each excavation round mainly included four steps as shown in Figure 4.

(i) Drilling: there were 135 blast holes drilled at the bottom of the shaft, including 15 cutting holes, 69 stope holes, and 52 contour holes.

(ii) Blasting and ventilation: for most excavation in rock, smooth blasting has to be designed based on geomechanical properties. For the ease of mucking, the blast holes were filled with about $465.6 \mathrm{~kg}$ emulsion explosive in total (a higher than typical amount), and a millisecond blasting method was applied. After blasting, the blast smoke was removed from the shaft using a ventilation procedure typically requiring tens of minutes to complete.

(iii) Mucking: it took about 4 hours to remove approximately $113 \mathrm{~m}^{3}$ of muck for each excavation round.

(iv) Lining: after mucking was completed, the lining formworks were moved down in the shaft, and fast- 


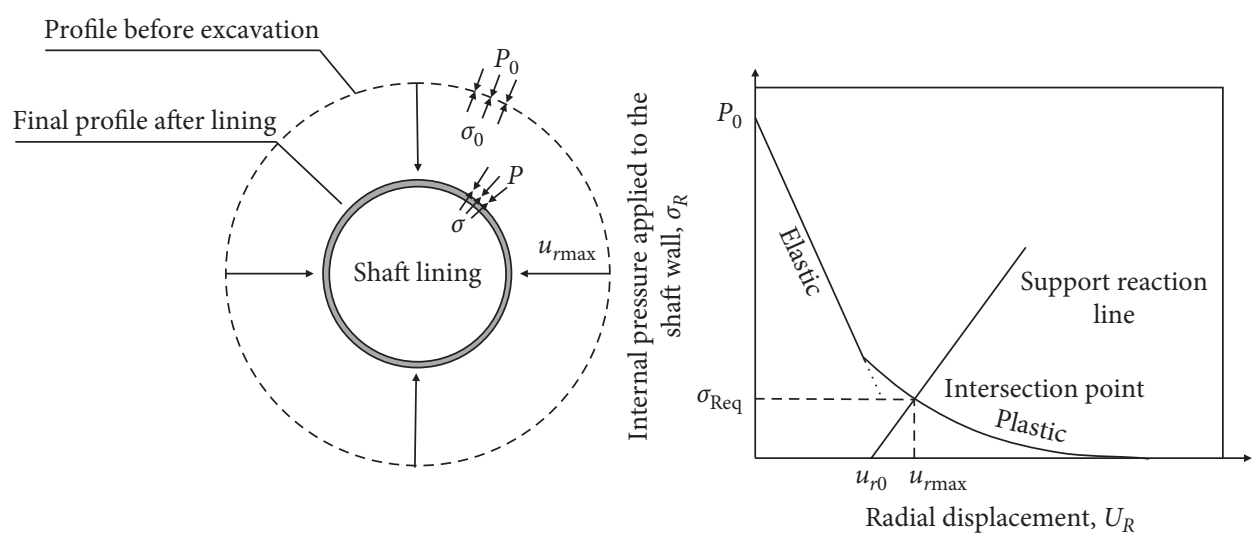

FIgURE 1: Schematic illustration of the convergence confinement method.
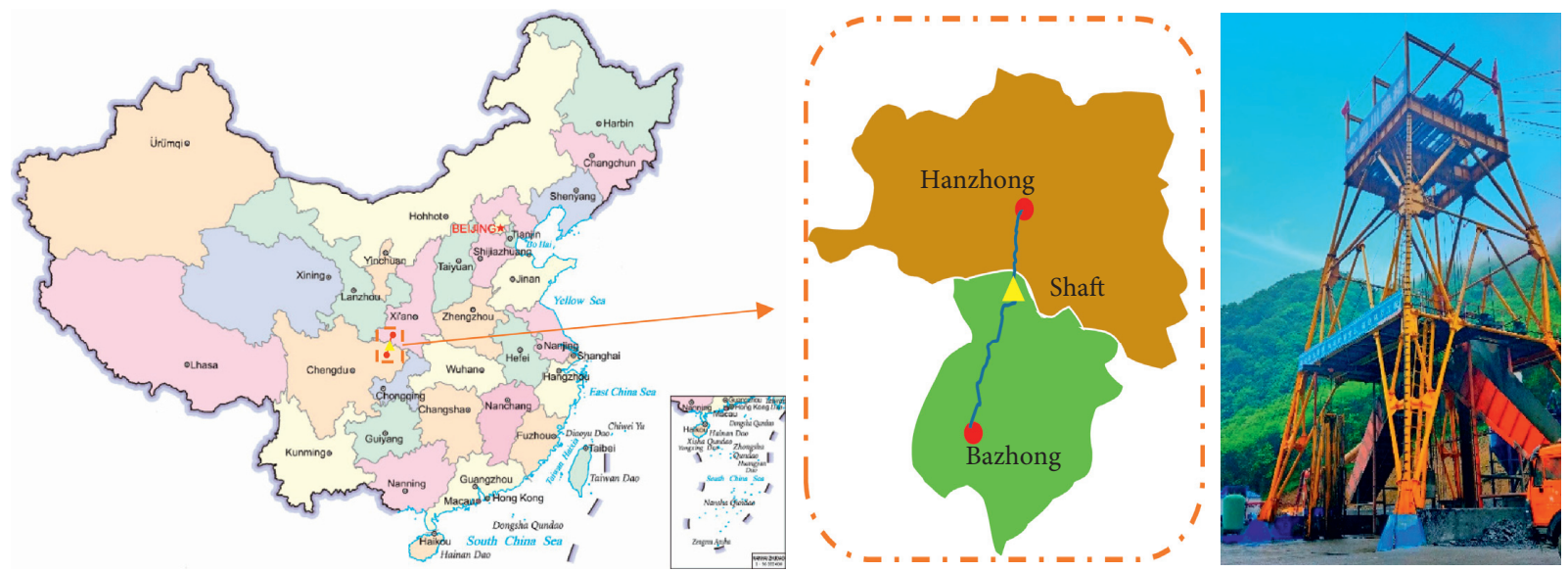

FIGURE 2: The geographical position of shaft.

TABLE 1: Intact rock mechanical properties.

\begin{tabular}{lcccccc}
\hline Parameters & $\sigma_{\mathrm{ci}}(\mathrm{MPa})$ & $\mathrm{E}(\mathrm{GPa})$ & $v$ & $m_{i}$ & $\sigma_{\mathrm{t}}(\mathrm{MPa})$ & $V_{\mathrm{p}}(\mathrm{km} / \mathrm{s})$ \\
\hline Values & 72.7 & 84.726 & 0.21 & 25 & 7.1 & 5.7
\end{tabular}

hardening concrete was poured. During the next blasting operation, the formworks also played an important role in protecting the fresh lining from the blast-induced damage.

Figure 5 shows the blasting schemes of the shaft. Three kinds of holes were drilled for the blasting: cutting holes, auxiliary holes, and contour holes. The parallel cut was used to break out the confinement of the face. The depths of the holes range from 3.0 to $4.2 \mathrm{~m}$.

The emulsion explosive and delay detonators are used in the blasting. Table 2 shows the blasting parameters.

\section{Field Measurements and Interpretation}

When using a drill and blast approach for shaft construction, blast-induced rock damage extends from the excavation boundary into the rock mass. Blast-induced rock damage leads to the degradation of the rock mass through the expansion of the original cracks and the creation of new cracks [35-37, 42, 43]. As a result, the strength and stiffness of the

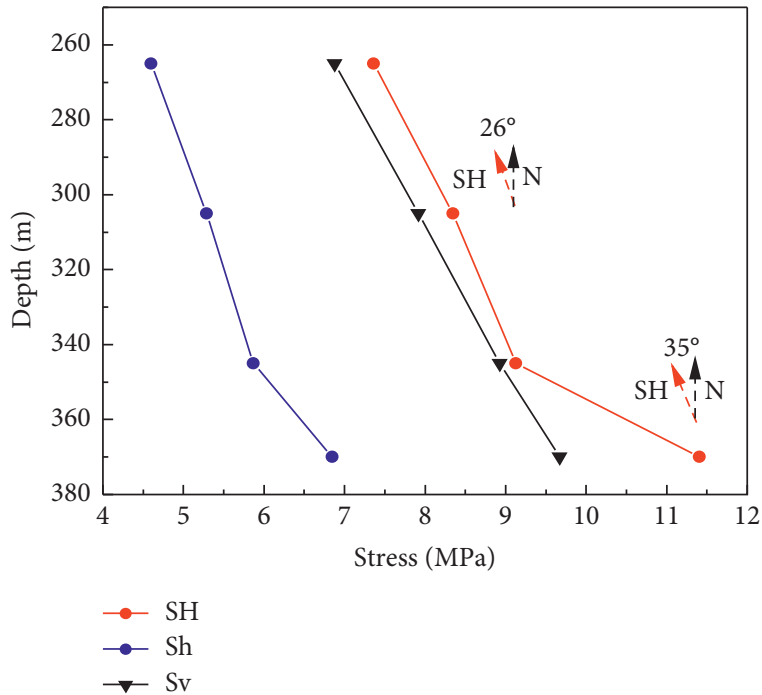

FIGURE 3: Diagram of in situ stress information (here SH: the maximum horizontal principal stress; Sh: the minimum horizontal principal stress; Sv: the vertical stress).

rock mass in the blast-induced damage zone are much lower than those of the intact rock and the undamaged rock mass. Malmgren et al. [44] carried out seismic measurements on 


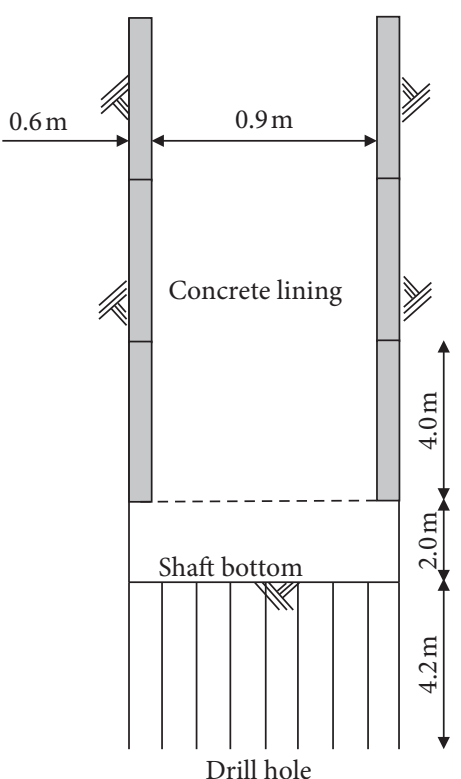

(a)

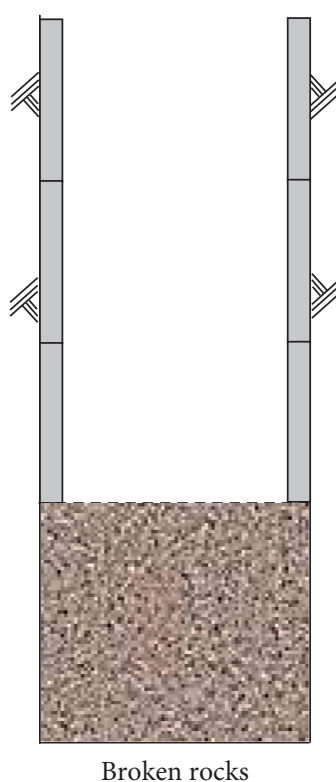

(b)

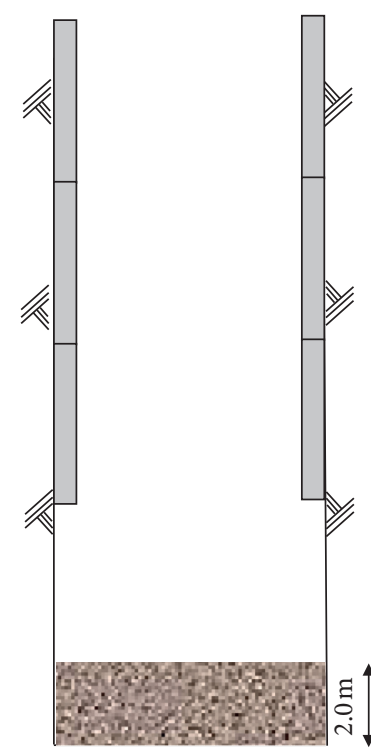

(c)

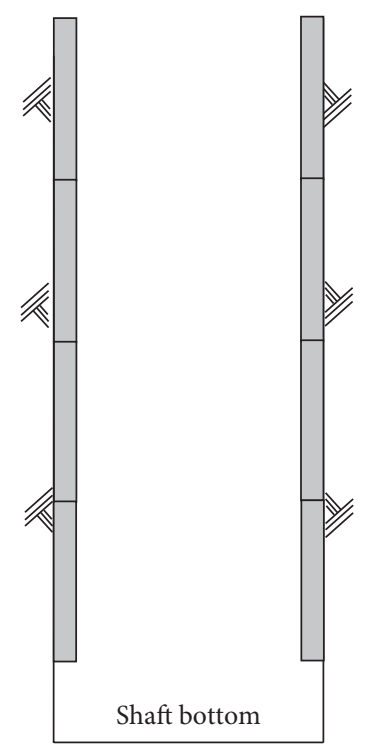

(d)

Figure 4: Shaft sinking procedure using the short-step method. (a) Stage 1. (b) Stage 2. (c) Stage 3. (d) Stage 4.

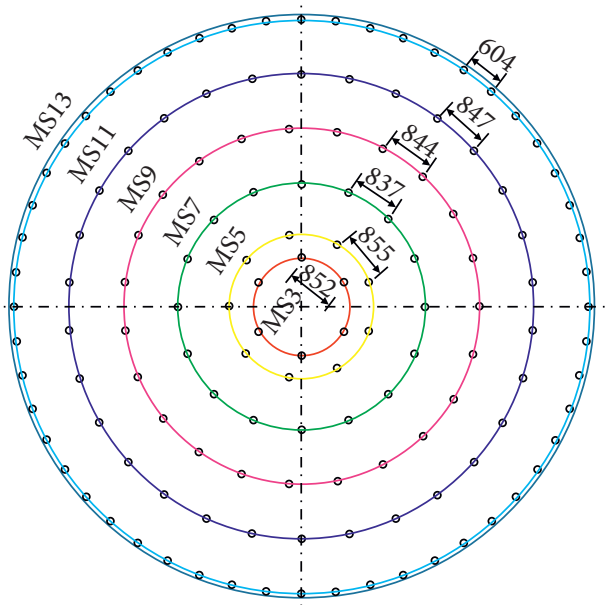

(a)

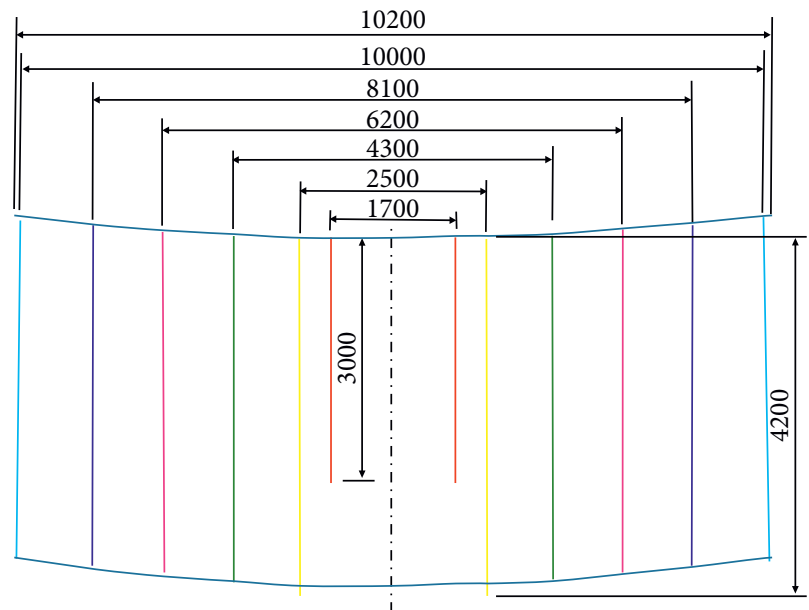

(b)

FIgURe 5: Typical blasting scheme for shaft excavation.

the damaged zone around a mine drift and found that the thickness of this zone behind the drift wall was $0.5 \mathrm{~m}-1.0 \mathrm{~m}$, and the magnitude of the Young's modulus of this zone was $50 \%$ to $90 \%$ of that of the intact rock. Sato et al. [45] also found that the seismic velocity of the damaged zone behind the drift wall was $65-70 \%$ of that of the intact rock through in situ experiments. In general, the damage zone extent, and severity will depend on the blasting practices utilized and the original (undamaged) rock mass characteristics.

In this study, ultrasonic tests were developed to evaluate the blast-induced damage depth around the shaft. There were four vertical positions (horizontal sections) at which ultrasonic tests were conducted. The tests were conducted using the RSM-RCT(B) test system developed by Sinorock
Technology Co., Ltd. with an excitation frequency of $50 \mathrm{kHz}$. At each test section, four boreholes were drilled with a depth of $2 \mathrm{~m}$ in the radial direction, as shown in Figure 6.

In each case, the test was carried out right after the mucking and completed before the lining formworks were advanced. The sensors were first placed at the bottom of the hole and then moved out slowly. During the test, the P-wave velocity was recorded at $10 \mathrm{~cm}$ intervals; the data collection process is illustrated in Figure 7.

Figure 8 shows the example of waveform obtained in measurement. The figure shows that the amplitude of wave received in damaged zone is much bigger than the result of no damaged zone. Meanwhile, the propagation velocity of damaged zone is much slower than the result of no damaged zone. 
TABLE 2: Blasting parameters.

\begin{tabular}{lcccccc}
\hline \multirow{2}{*}{ Type of shots } & \multicolumn{2}{c}{ Borehole } & \multicolumn{2}{c}{ Detonation } & \multicolumn{2}{c}{ Explosive allocation } \\
& Number & Angle $\left({ }^{\circ}\right)$ & Segment & Delay time (ms) & Charge per shot & Max. charge per delay (kg) \\
\hline Cutting holes & 6 & 90 & MS3 & 50 & 4.0 & 24.0 \\
Cutting holes & 9 & 90 & MS5 & 110 & 4.8 & 43.2 \\
Auxiliary holes & 16 & 90 & MS7 & 200 & 4.0 & 64.0 \\
Auxiliary holes & 23 & 90 & MS9 & 310 & 4.0 & 92 \\
Auxiliary holes & 30 & 90 & MS11 & 460 & 2.4 & 120.0 \\
Contour holes & 52 & 91 & MS13 & 650 & 124.8 \\
\hline
\end{tabular}

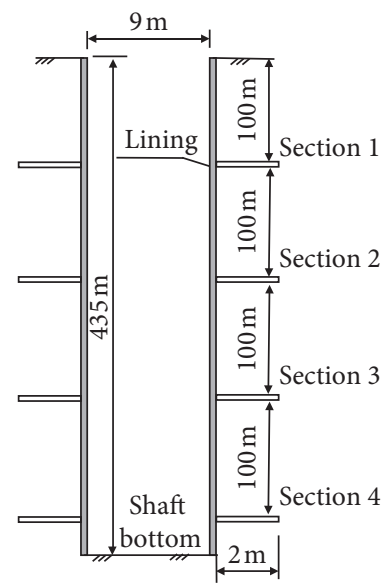

(a)
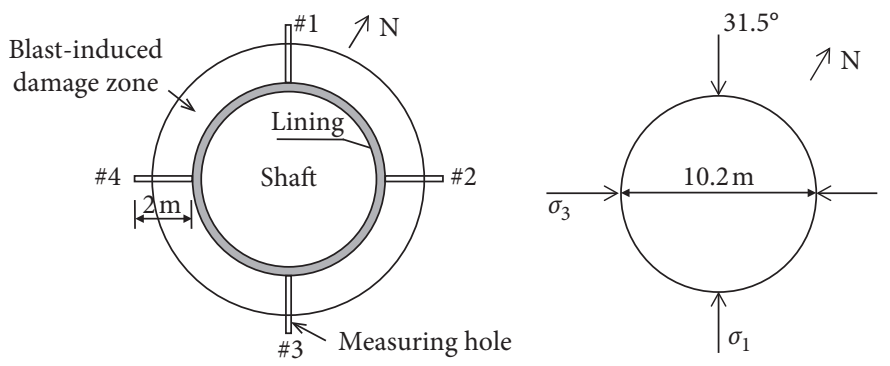

(b)

(c)

FIGURE 6: Sketch of the ultrasonic test hole layout (not to scale).

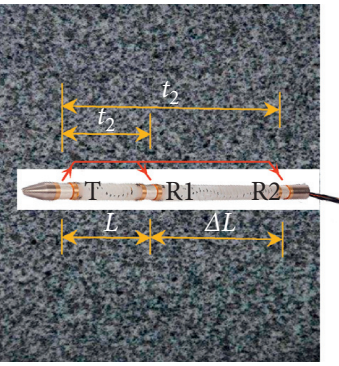

(a)

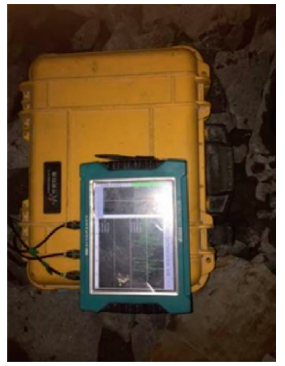

(b)

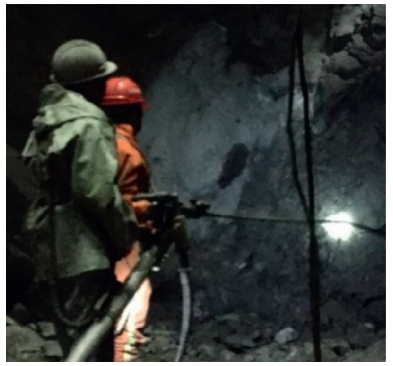

(c)

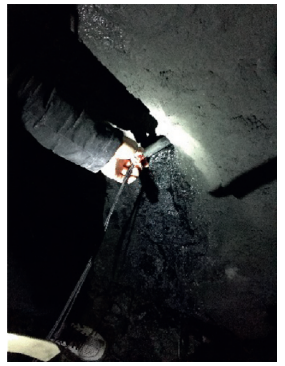

(d)

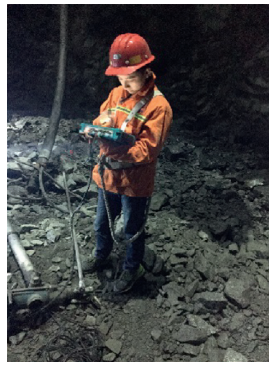

(e)

Figure 7: Testing process of ultrasonic tests: (a) test schematic diagram; (b) test equipment; (c) drilling test hole; (d) move the placement of the sensor; (e) data collection.

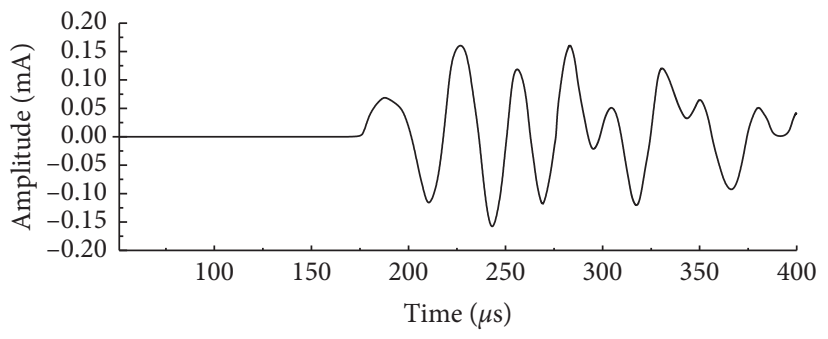

(a)

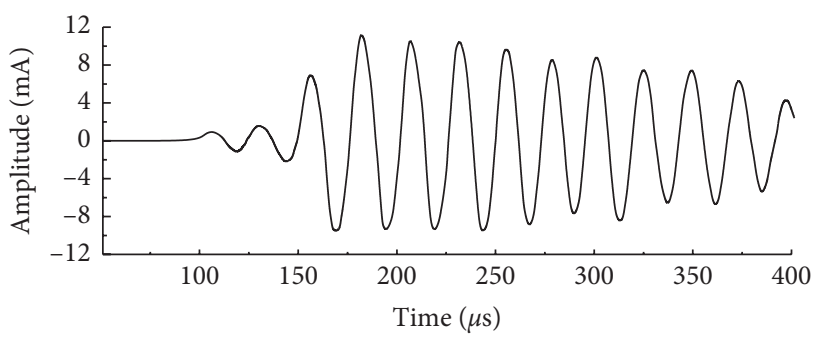

(b)

Figure 8: The waveform obtained in BDZ (a) and out of BDZ (b). 


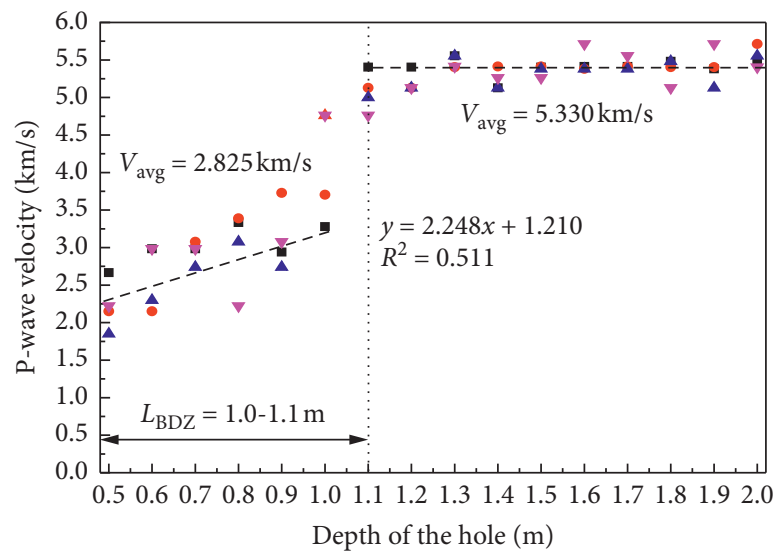

Section 1

- \#1 measuring hole

- \#2 measuring hole

- \#3 measuring hole

$\checkmark$ \#4 measuring hole

(a)

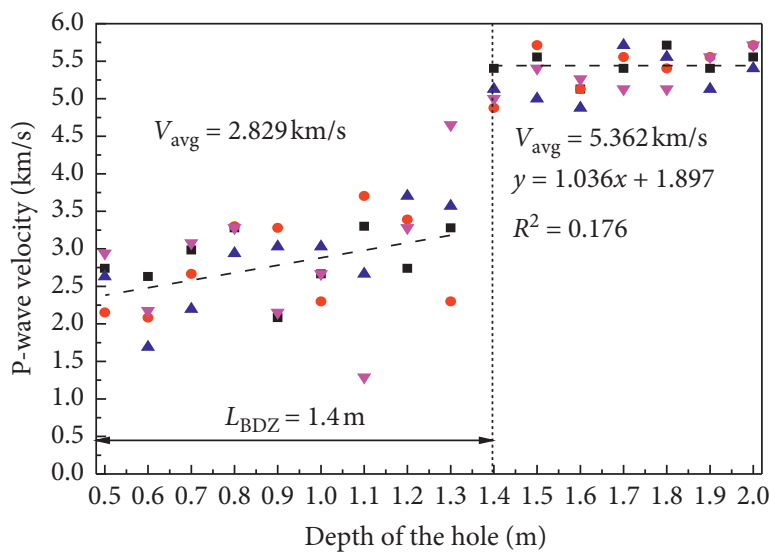

Section 3

- \#1 measuring hole

- \#2 measuring hole

- \#3 measuring hole

v \#4 measuring hole

(c)

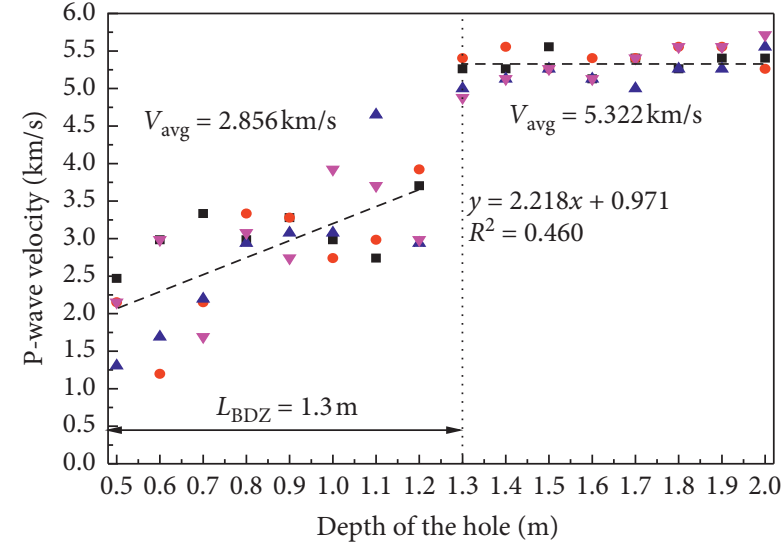

Section 2

- \#1 measuring hole

- \#2 measuring hole

- \#3 measuring hole

v \#4 measuring hole

(b)

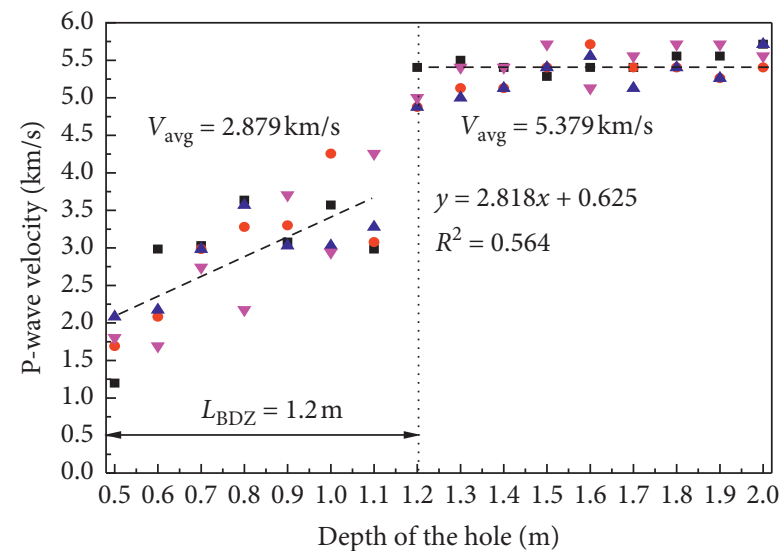

Section 4

$\begin{array}{ll}\text { - \#1 measuring hole } & \text { A } \# 3 \text { measuring hole } \\ \text { - \#2 measuring hole } & \boldsymbol{\nabla} \# 4 \text { measuring hole }\end{array}$

(d)

Figure 9: P-wave velocity $\left(V_{\mathrm{p}}\right)$ in the test holes: (a) section 1; (b) section 2; (c) section 3; (d) section 4.

The ultrasonic test results are shown in Figure 9. The results illustrate that the rock mass surrounding the shaft can be divided into two different zones according to the $\mathrm{P}$-wave velocity $\left(V_{\mathrm{p}}\right)$. The region with $\mathrm{P}$-wave velocity values on the order of $2.8 \mathrm{~km} / \mathrm{s}$ is referred to as the blasting-induced damage zone (BDZ). Further from the excavation, the average $\mathrm{P}$-wave velocity is $5.3 \mathrm{~km} / \mathrm{s}$, which is much higher than in the blasting-induced damage zone (BDZ); however, the average $\mathrm{P}$-wave velocity is slower than the velocity of intact rock $(5.7 \mathrm{~km} / \mathrm{s})$, and the difference is mainly caused by the noncontinuity and heterogeneity of rock mass. Generally, rock mass is the synthesis of intact rock and discontinuities (i.e., faults, joints, and other structural features), and studies have shown that the presence of the joints not only induces wave amplitude attenuation but also decreases the wave propagation velocity [46]. The distance from the BDZ boundary to the shaft wall $\left(L_{\mathrm{BDZ}}\right)$ can be distinguished easily using the P-wave velocity $\left(V_{\mathrm{p}}\right)$ measurements in Figure 9.
Based on these results, it can be concluded that the orientation of the principal stress has minimal influence on the $\mathrm{P}$-wave velocity trends at a given location. This is consistent with the fact that it is not expected that notable rock mass degradation would occur at the given cover depths due to in situ stress redistribution and concentration around the excavation, suggesting that the blast process is the principal factor that controls rock mass damage. This is also consistent with the fact that there does not appear to be any general correlation between the damaged zone size and cover depth. The results also show that there is a linear gradient in $\mathrm{P}$-wave velocity away from the excavation within the BDZ. Although some variation in $\mathrm{P}$-wave velocity could be attributed to increased confining stress away from the excavation, given the magnitude of velocity variation within the BDZ, it is likely that this $\mathrm{P}$-wave velocity gradient is directly related to the severity of rock mass damage induced by blasting activities. 
The appropriate evaluation of mechanical properties of a rock mass is critically important for safe and economical design of engineering system; for the analysis conducted by numerical method (i.e., the finite element and finite difference methods), the deformability and strength of rock mass is quite important. The mechanical parameters of intact rock can be determined by laboratory tests like triaxial and shear test; however, the interaction between intact rock blocks and discontinuous is very complex, and it is difficult to capture the mechanical properties of rock mass by laboratory-based measurements [47]. Several empirical relationships have been proposed for estimating the value of rock mass deformation modulus [48-50]. Barton [51] suggested the following equation to link the static deformation modulus of rock mass and the P-wave velocity:

$$
E=10^{\left(V_{\mathrm{p}}-0.5\right) / 3} \text {, }
$$

where the units of $E$ is $\mathrm{GPa}, V_{\mathrm{p}}$ is $\mathrm{P}$-wave velocity in $\mathrm{km} / \mathrm{s}$. The average $V_{\mathrm{p}}$ of the $\mathrm{BDZ}$ rocks was tested to be $2.83 \mathrm{~km} / \mathrm{s}$; based on this value and equation (1), the static deformation modulus of the $\mathrm{BDZ}$ rock mass can be estimated to be 6.0 GPa.

The geological strength index (GSI) is a classification index that can be used to describe the structural characteristics of rock mass [52]. In order to use the Hoek-Brown criterion for estimating the strength and deformability of jointed rock masses, the GSI values of the rock mass have to be estimated. Based on accepted methods for GSI estimation, the GSI of the rock mass being considered in this study was determined to be 72 [53]. Cai et al. [54] suggested that the residual $\mathrm{GSI}_{\mathrm{r}}$ value can be expressed empirically as a function of the peak GSI value:

$$
\mathrm{GSI}_{\mathrm{r}}=\mathrm{GSI} \cdot \exp (-0.0134 \mathrm{GSI}) \text {. }
$$

According to the relationship, the residual GSIr of BDZ rocks can be estimated. According to equation (2), an undamaged ("peak") GSI value of 72 corresponds to a damaged ("residual") GSI value of 27. Hoek et al. introduced a new parameter $D$ to reflect the degree of disturbance to which the rock mass has been subjected by blast damage [52]. However, because it is very difficult to quantify the disturbance coefficient $D$ [55], blast damage was accounted for by using a "residual" GSI (and $D=0$ ) as described above.

\section{Convergence-Confinement Curves (CCC) of the Shaft Rocks}

As mentioned above, The CCM is a useful method to estimate the loads on a vertical shaft. In this section, the CCM is used to calculate the radial loads acting on the lining by considering the effect of the BDZ and the influence of principal stress direction.

4.1. Constitutive Model and Material Parameters. A finitedifference model was constructed in FLAC3D to obtain the CCC of the quartz diorite rock mass surrounding the shaft. The widely used Hoek-Brown failure criterion was applied in the numerical model to represent the strength of the rock mass. The static deformation modulus of the undamaged rock mass was calculated by equation (3) according to Hoke et al. [52]:

$$
E=\left(1-\frac{D}{2}\right) \sqrt{\frac{\sigma_{\mathrm{ci}}}{100}} \cdot 10^{((\mathrm{GSI}-10) / 40)},
$$

here $D$ is the disturbance coefficient, and for undamaged rock mass, $D$ is 0 .

Both of these values are much smaller than the intact modulus (laboratory value) because of the influence of the preexisting fractures in the undamaged rock mass and the blasting-induced fractures in the damaged rock mass. Based on the GSI of the BDZ rock mass as estimated by equation (2) as well as the value of $m_{i}$, the value of the Hoek-Brown constants $m_{\mathrm{b}}, s$ and $a$ for the rock mass can be calculated using the following equations [52]:

$$
\begin{aligned}
m_{\mathrm{b}} & =m_{i} \exp \left(\frac{\mathrm{GSI}-100}{28}\right), \\
s & =\exp \left(\frac{\mathrm{GSI}-100}{9}\right), \\
a & =0.5 \text { for GSI }>0.5,
\end{aligned}
$$

where $m_{i}$ is 25 for the quartz diorite [56].

4.2. Mesh and Boundary Conditions. In cases where the horizontal tectonic stresses are not notably anisotropic, axisymmetric model conditions can sometimes be used to simulate shaft sinking. However, the axisymmetric model is not suitable for this case because in situ stress measurements showed that the principal stress is horizontal due to tectonic loading. Instead, a three-dimensional numerical model including the initial tectonic stress was used to simulate the full shaft-sinking sequence. Considering the symmetry of the problem, the numerical model of the shaft sinking was simplified to represent a quarter-symmetry condition. Assuming that the orientation of major in situ principal stress is in line with $X$-direction and the depth is in the $Z$-direction, a three-dimensional numerical model was developed using the explicit finite difference program FLAC3D as shown in Figure 10. The model has a height of $450 \mathrm{~m}$ and a width of $200 \mathrm{~m}$ to minimize any adverse boundary effects on the model results. The top side of the model is traction free, and the other sides are fixed to prevent motion perpendicular to their orientations.

Given the mesh dependence of inelastic models, it is critical to utilize a relatively fine mesh in areas where stress and strain gradients may be large. Accordingly, the mesh size was set to be fine near the shaft and coarse near the boundary. During initial model testing, several mesh sizes were used to ensure that the results are reasonable. A minimum element size of $10 \mathrm{~cm}$ was used in the radial direction near the shaft lining and BDZ area for all analyses. Referring to the horizontal in situ principal stresses in Figure 3, the in situ principal stresses in the $X$-direction and $Y$-direction were assumed to have a linear relationship with depth in the model. 


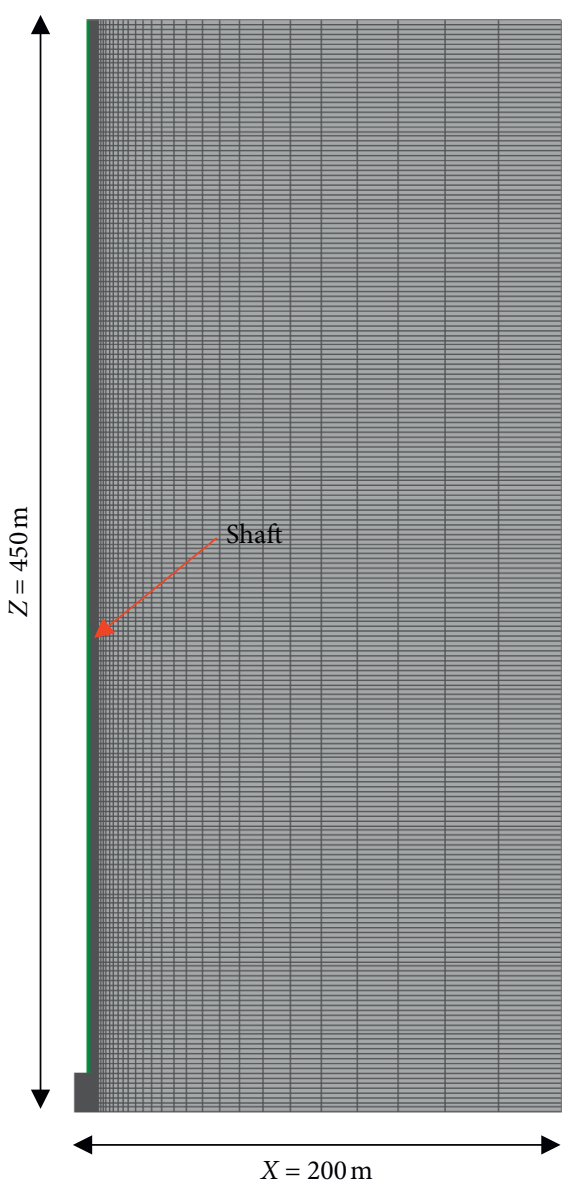

(a)

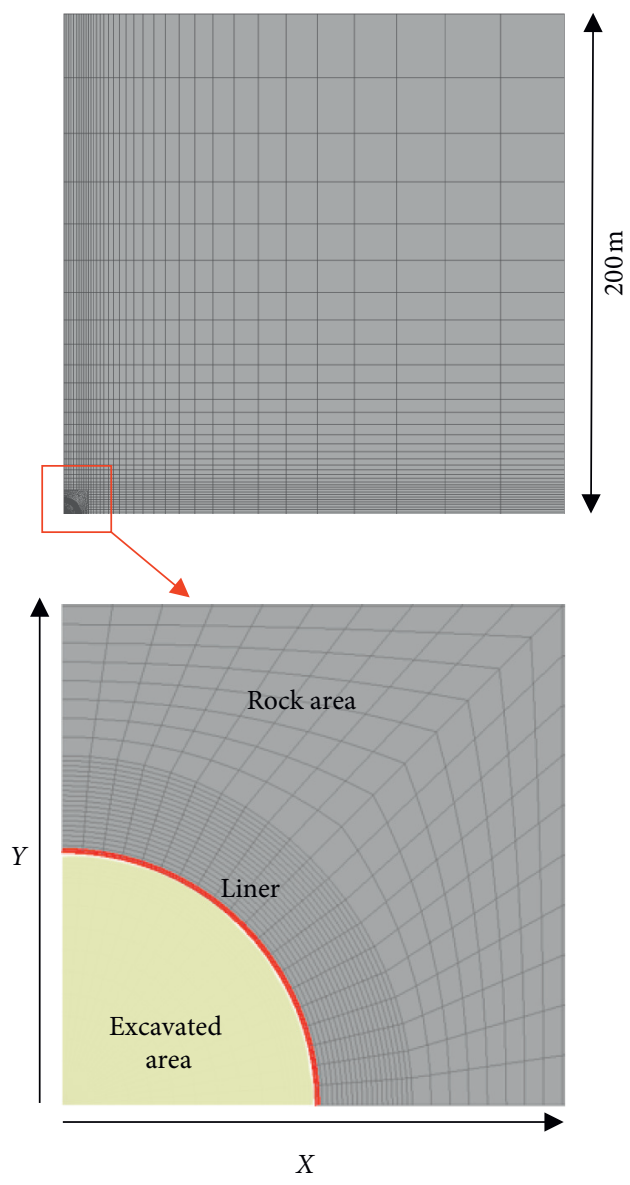

(b)

FIgURE 10: 3D vertical shaft model mesh layout.

4.3. Characteristic Curves of the Shaft Rocks. When the convergence confinement method (CCM) is used to estimate the radial loads on the shaft lining, the relationship of the radial ground displacement, $U_{\mathrm{R}}$, and the equivalent internal pressure acting on the rock mass, $P_{i}$, need to be obtained first. This relationship is represented by the convergenceconfinement curve (CCC), which is important for the analysis of the interaction between the rocks and the shaft lining $[25,26]$. The CCC of the rocks around the shaft was calculated using the following sequence in the aforementioned numerical model: (i) initiate the model with zero displacement and initial in situ stress, including gravitational loading; (ii) null the shaft elements to be excavated and insert the BDZ after the excavation face passed each section to simulate the damage of rock mass, the extent of the BDZ in numerical analysis was determined based on the result of seismic survey; (iii) apply radial pressure to the excavation surface. Changing the pressure from the initial stress gradually to zero, the relationship of the radial displacement of surrounding rocks and the internal pressure on the rock mass of different direction was obtained, as shown in Figure 11.

Figure 11 shows that the BDZ has a large effect on the CCC of the shaft rocks. For the cases with no BDZ, the CCCs are linear, indicating fully elastic behavior. When the $\mathrm{BDZ}$ is considered in the models, the CCC of the shaft rocks can be divided into two stages by the critical pressure, $P_{\mathrm{E}-\mathrm{P}}$. In the first stage, the internal pressure $P$ on the shaft rocks is bigger than the critical pressure, $P_{\mathrm{E}-\mathrm{P}}$, and the internal pressure, $P$, has a linear relationship with the radial ground displacement, $U_{\mathrm{R}}$. However, if the internal pressure, $P$, is less than the critical pressure, $P_{\mathrm{E}-\mathrm{P}}$, a plastic zone develops in the rock mass due to the lower strength of the BDZ rock mass.

The difference of the initial ground stress in the $X$-direction and $Y$-direction results in different CCCs when different orientations are considered around the shaft. It was found that in the $Y$-direction, the radial displacement at a given $P$ is much smaller than that in the $X$-direction and the slope of the CCC is bigger, which suggests that the overall ground response to excavation is effectively stiffest in this orientation.

\section{Numerical Analysis of Vertical Shaft}

In addition to generating the basic CCCs for the shaft, the previously described numerical model was used to conduct an analysis of the shaft considering the full excavation and support sequence. To simulate the lining installed after every excavation cycle, a $600-\mathrm{mm}$-thick annulus of unreinforced concrete is used. The shaft lining is assumed to be linear 

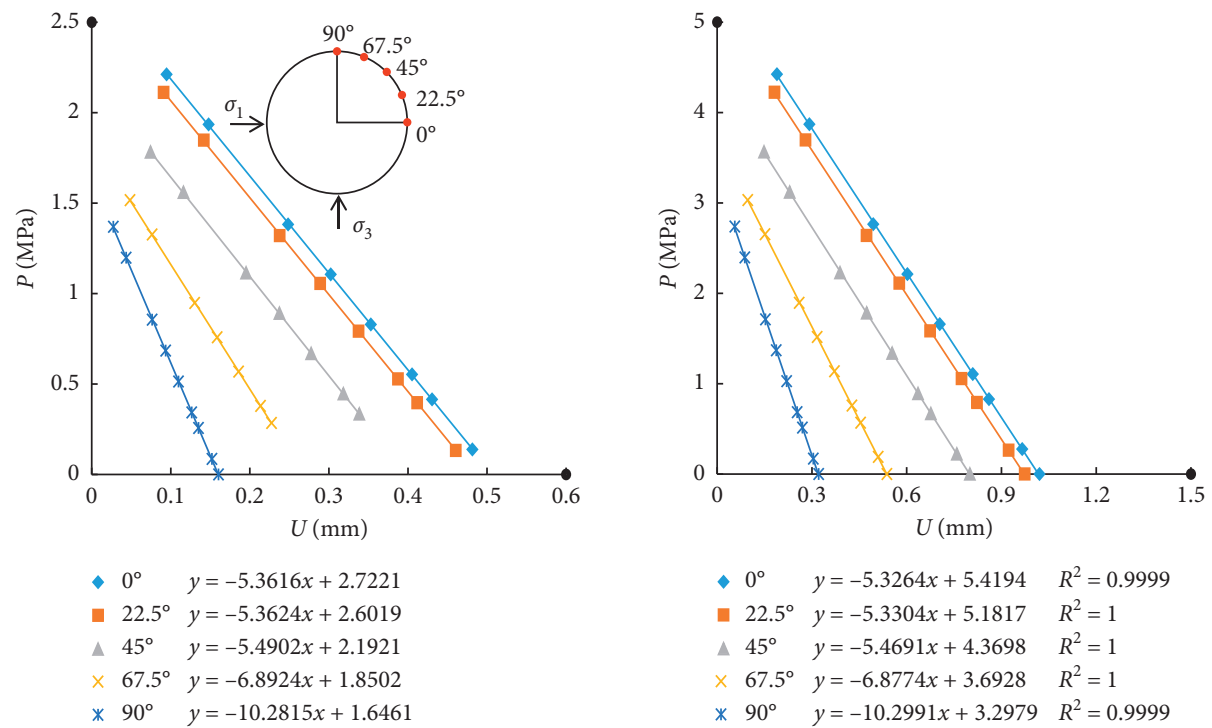

$$
\begin{array}{lll}
0^{\circ} & y=-5.3264 x+5.4194 & R^{2}=0.9999 \\
22.5^{\circ} & y=-5.3304 x+5.1817 & R^{2}=1 \\
\triangle 45^{\circ} & y=-5.4691 x+4.3698 & R^{2}=1 \\
\times 67.5^{\circ} & y=-6.8774 x+3.6928 & R^{2}=1 \\
* 90^{\circ} & y=-10.2991 x+3.2979 & R^{2}=0.9999
\end{array}
$$
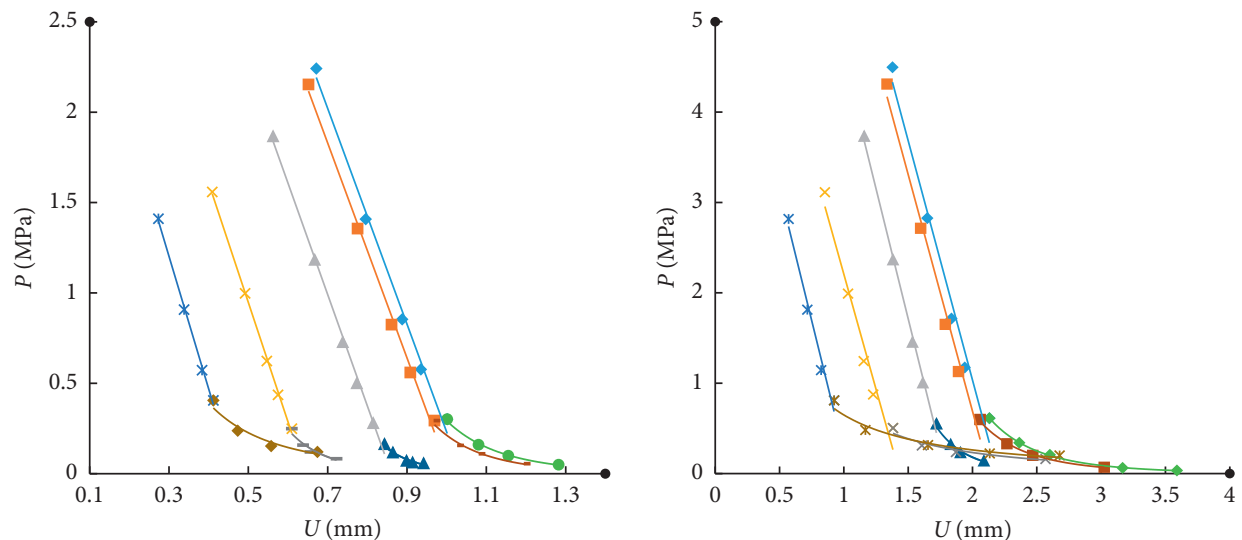

$0^{\circ}-1 \quad y=-5.9648 x+6.1957$

- $0^{\circ}-2 \quad y=0.2928 x^{-7.27}$

$22.5^{\circ}-1 \quad y=-5.9426 x+5.9888$

- $22.5^{\circ}-2 \quad y=0.2126 x^{-7.78}$

$445^{\circ}-1 \quad y=-6.1586 x+5.3023$

$\Delta 45^{\circ}-2 \quad y=0.0276 x^{-9.99}$

$67.5^{\circ}-1 \quad y=-6.6007 x+4.2475$

- $67.5^{\circ}-2 \quad y=0.0099 x^{-6.28}$

* $90^{\circ}-1 \quad y=-7.3368 x+3.4038$

- $90^{\circ}-2 \quad y=0.0416 x^{-2.44}$

$$
\begin{array}{lll}
0^{\circ}-1 & y=-5.316 x+11.635 & R^{2}=0.9817 \\
0^{\circ}-2 & y=43.1527 x^{-5.62} & R^{2}=0.999 \\
\text { - } 22.5^{\circ}-1 & y=-5.2422 x+11.1713 & R^{2}=0.9869 \\
\text { - } 22.5^{\circ}-2 & y=32.282 x^{-5.57} & R^{2}=0.9984 \\
\Delta 45^{\circ}-1 & y=-5.7554 x+10.3494 & R^{2}=0.9967 \\
\text { А } 45^{\circ}-2 & y=22.714 x^{-6.96} & R^{2}=0.9845 \\
\times 67.5^{\circ}-1 & y=-5.0867 x+7.2923 & R^{2}=0.966 \\
-67.5^{\circ}-2 & y=0.7857 x^{-1.75} & R^{2}=0.9431 \\
\text { * } 90^{\circ}-1 & y=-5.7856 x+6.0338 & R^{2}=0.9812 \\
* 90^{\circ}-2 & y=0.6491 x^{-1.31} & R^{2}=0.9659
\end{array}
$$

(b)

Figure 11: Continued. 


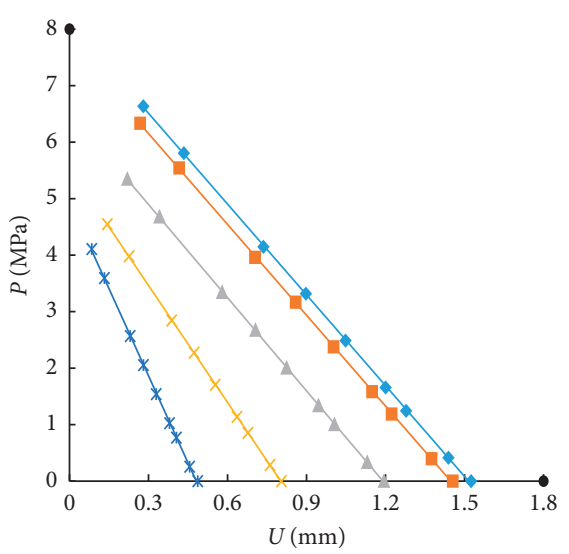

$$
\begin{array}{lll}
0^{\circ} & y=-5.3564 x+8.1168 & R^{2}=0.9999 \\
22.5^{\circ} & y=-5.3581 x+7.7597 & R^{2}=0.9999 \\
\triangle 45^{\circ} & y=-5.5003 x+6.5469 & R^{2}=0.9999 \\
\times 67.5^{\circ} \quad y=-6.8969 x+5.5308 & R^{2}=0.9999 \\
* 90^{\circ} \quad y=-10.2724 x+4.9463 & R^{2}=0.9997
\end{array}
$$

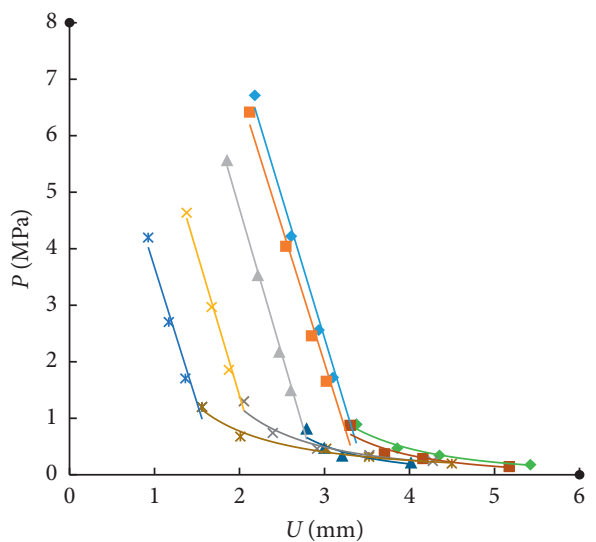

$$
\begin{array}{lll}
0^{\circ}-1 & y=-4.9715 x+17.3341 & R^{2}=0.9877 \\
0^{\circ}-2 & y=45.3017 x^{-3.31} & R^{2}=0.9829 \\
22.5^{\circ}-1 & y=-4.8013 x+16.3823 & R^{2}=0.9848 \\
\text { — } 22.5^{\circ}-2 & y=66.2632 x^{-3.79} & R^{2}=0.9398 \\
\triangle 45^{\circ}-1 & y=-5.1658 x+15.0367 & R^{2}=0.9948 \\
\triangle 45^{\circ}-2 & y=21.9982 x^{-3.42} & R^{2}=0.8918 \\
\times 67.5^{\circ}-1 & y=-5.0542 x+11.5016 & R^{2}=0.9885 \\
\times 67.5^{\circ}-2 & y=5.5413 x^{-2.21} & R^{2}=0.9717 \\
* 90^{\circ}-1 & y=-4.8085 x+8.4809 & R^{2}=0.9711 \\
* 90^{\circ}-2 & y=2.3429 x^{-1.67} & R^{2}=0.9774
\end{array}
$$

(c)

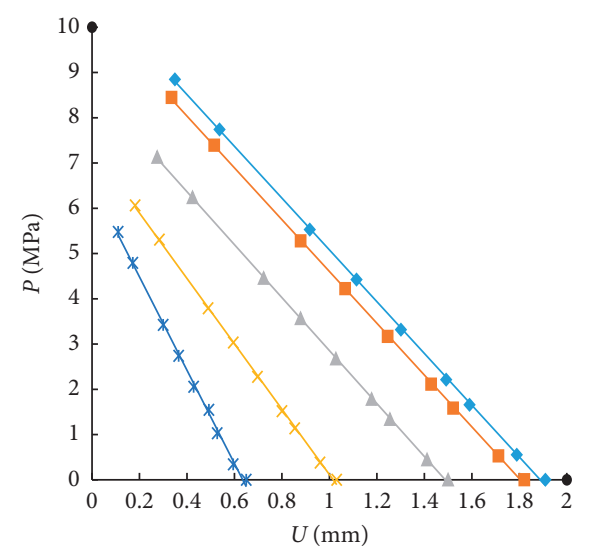

$$
\begin{array}{lll}
0^{\circ} & y=-5.7191 x+10.7993 & R^{2}=0.9997 \\
22.5^{\circ} & y=-5.7218 x+10.3271 & R^{2}=0.9998 \\
\triangle 45^{\circ} & y=-5.8522 x+8.7073 & R^{2}=0.9998 \\
\times 67.5^{\circ} & y=-7.2262 x+7.3412 & R^{2}=0.9995 \\
* 90^{\circ} & y=-10.3113 x+6.5465 & R^{2}=0.9981
\end{array}
$$

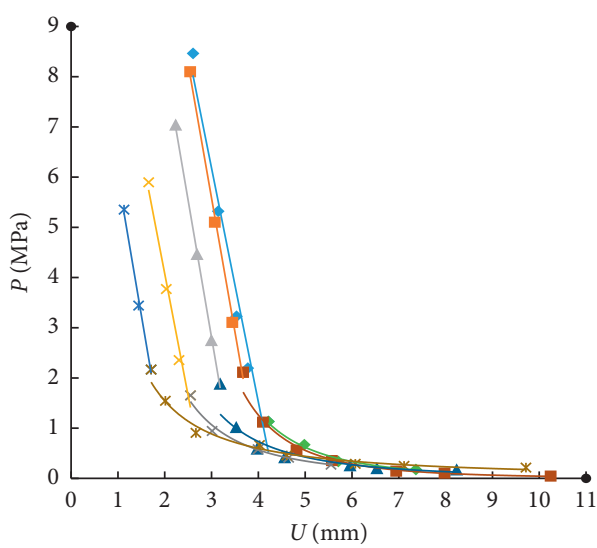

$$
\begin{aligned}
& \text { - } 0^{\circ}-1 \quad y=-4.6586 x+20.1533 \quad R^{2}=0.971 \\
& \text { - } 0^{\circ}-2 \quad y=144.1021 x^{-3.39} \quad R^{2}=0.9827 \\
& \text { - 22.5 }-1 \quad y=-5.3367 x+21.5914 \quad R^{2}=0.9978 \\
& \text { - 22.5 }-2 \quad y=198.8531 x^{-3.65} \quad R^{2}=0.9905 \\
& 45^{\circ}-1 \quad y=-5.4681 x+19.2041 \quad R^{2}=0.999 \\
& \text { \ } 45^{\circ}-2 \quad y=21.5983 x^{-2.44} \quad R^{2}=0.9193 \\
& \times 67.5^{\circ}-1 \quad y=-4.8523 x+13.7812 \quad R^{2}=0.9843 \\
& \times 67.5^{\circ}-2 \quad y=12.0611 x^{-2.21} \quad R^{2}=0.9897 \\
& \text { * } 90^{\circ}-1 \quad y=-5.5126 x+11.5226 \quad R^{2}=0.9948 \\
& \text { * } 90^{\circ}-2 \quad y=3.9978 x^{-1.37} \quad R^{2}=0.9764
\end{aligned}
$$

(d)

Figure 11: Best-fitting CCCs at different depths: (a) section 1; (b) section 2; (c) section 3; (d) section 4 . The upper image shows the results when the BDZ is ignored, whereas the lower image represents results from models that explicitly include the BDZ.

elastic with a Poisson's ratio of 0.2 and a density of $2400 \mathrm{~kg} /$ $\mathrm{m}^{3}$. For a prefabricated support structure, like concrete lining segments, the mechanical parameters after installation can be considered to be a fixed value [57], whereas the Young's Modulus values are time dependent for cast-inplace concrete. In this case, the shaft lining was cast in situ after excavation. Given that the entire excavation cycle takes about 24 hours, it is expected that some of the rock mass deformations behind the lining would have occurred during the early age of the concrete [58]. Wang [59] studied the evolution of concrete's Young's Modulus during its early age and found that the Young's Modulus increases with time until it reaches a relatively stable value (generally accepted to be equivalent to the value on the $28^{\text {th }}$ day). In this study, the $E_{\mathrm{t}} / E_{28}$ ratios considering $E_{\mathrm{t}}$ at ages of $1,3,7$, and 14 days were found to be $0.577,0.701,0.762$, and 0.869 , respectively, based on concrete testing. To simplify the modeling process, the concrete modulus evolution process was treated as follows: Stage I corresponds to a Young's Modulus of 18.2 GPa for the first day after installation; Stage II corresponds to a Young's Modulus of $24.8 \mathrm{GPa}$ from $2^{\text {th }}$ to $27^{\text {th }}$ days after installation; Stage III corresponds a Young's Modulus of $31.5 \mathrm{GPa}$ from the $28^{\text {th }}$ day after installation onwards. To implement this staged procedure in the numerical model, 
the units of "days" were converted to distance using the known 24 hour cycle time for one advance of the shaft. The monitoring points for radial displacement and structural internal force are shown in Figure 12.

5.1. Radial Displacement Induced by Shaft Sinking. Radial displacement of the ground is the key parameter that controls the development of load in the shaft lining. The radial displacements at excavation depths of $100 \mathrm{~m}, 200 \mathrm{~m}$, $300 \mathrm{~m}$, and $400 \mathrm{~m}$ are shown in Figure 13. The results clearly show that the radial displacement increases with the shaft depth, and the radial displacement along the shaft outline changes with the angular position around the shaft; the maximum displacement occurred at the major horizontal stress orientation for all depths, whereas the minimum displacement occurred at the minor horizontal stress orientation. In addition, for the case where no BDZ was modeled, the radial displacement is almost exclusively elastic in nature, meaning the displacement value increases linearly with the depth in this case. When incorporated into the models, the inelastic behavior of the BDZ resulted in increased displacement.

5.2. Radial Load Estimation. For shafts located in isotropic stress fields, the loads acting on the lining can be considered as purely radial loads and the shear loads can be neglected. However, for the current case study with an anisotropic in situ stress field and a full bond between the rock mass and the concrete lining, the tangential displacement of surrounding rock may produce appreciable shear loads.

In the model, the axial forces of the lining were monitored and used to calculate loads induced by the deformation of the surrounding rock. For comparison, the radial loads calculated based on the CCC results were obtained (see Figure 14, compression stress is positive). The results show that the radial loads calculated by CCC increased with effective depth, but every measurement point had a different rate of increase as a function of effective depth. The distribution of radial loads is highly asymmetric, and the lowest radial loads appeared in the minimum principal stress direction, whereas the largest radial loads appeared at or near the maximum principal stress direction. In addition, the radial loads in the case without the $\mathrm{BDZ}$ are bigger than those in the case with the BDZ, as expected.

Figure 15 shows the distributions of the axial force and bending moment of the lining in the numerical model at different depths. As shown in Figure 15, for the cases with and without the BDZ, the axial force increases rapidly from the minimum principal stress direction to the maximum principal stress direction. The ratios of maximum thrust force to minimum thrust force (RMM) corresponding to the $100 \mathrm{~m}$, $200 \mathrm{~m}, 300 \mathrm{~m}$, and $400 \mathrm{~m}$ depth cases were $2.77,2.60,2.48$, and 2.37 , respectively, for the case of without the $\mathrm{BDZ}$, and 2.61 , $1.88,1.59$, and 1.43 , respectively, for the case with the BDZ. Additionally, in comparison to the results of the case where the $\mathrm{BDZ}$ is neglected, the minimum axial force on the lining increased approximately $30.2 \%, 36.7 \%, 73.0 \%$, and $102.5 \%$ at shaft depths of $100 \mathrm{~m}, 200 \mathrm{~m}, 300 \mathrm{~m}$, and $400 \mathrm{~m}$, respectively.

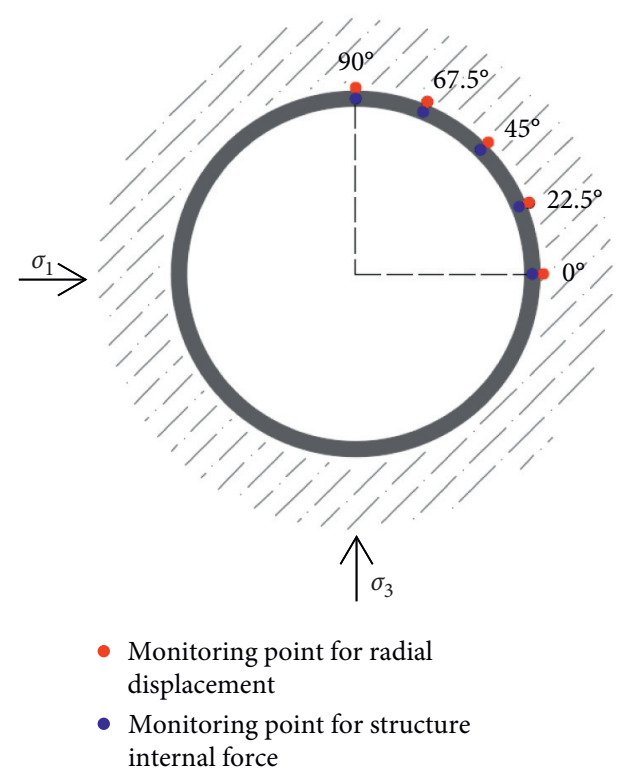

FIGURE 12: Layout of monitoring points.

In order to isolate the contribution of shear loads to the axial force of lining, the radial loads determined using the CCC approach were then compared with the axial force of the lining as determined using the fully sequenced numerical model (see Figure 16). In both the cases considering the BDZ and not considering the $\mathrm{BDZ}$, the axial forces were higher in the fully sequenced model than would be predicted assuming no shear load contribution to the axial force. When the BDZ was not considered, the degree of axial load underestimation was found to increase as a function of excavation depth, whereas when the $\mathrm{BDZ}$ was considered, the CCC approach consistently underestimated the axial force by a little more than $40 \%$.

Figure 17 shows the distribution of shear stress of surrounding rock, and Figure 18 shows the stress distribution in the concrete lining. As the results shown, the shear stresses acting on the lining vary as a function of angle, which indicates that the tangential deformation of surrounding rock is nonhomogenous. In the case that the $\mathrm{BDZ}$ was ignored, the maximum shear stress was found to exist at the rock-lining boundary, whereas when the BDZ was considered, the maximum shear stress exists at the boundary between the BDZ and the undamaged rock mass.

It should be noted that apart from $\mathrm{BDZ}$, there are many factors that can affect the stability of shaft too. In general, these factors can be classified into geological factors and construction factors. Geological factors, including rock properties (i.e., shear strength and compressive strength) and structural features, like bedding planes, faults, joints, and folds have dominant effects on the excavate operations. In addition, construction factors, including excavation spans, and supporting measures may also affect the stability of shafts. Although these effects can be considered to affect the stability of the shaft, the target of this research was to investigate the extent of the BDZ, so these addition factors were not considered in this study. 

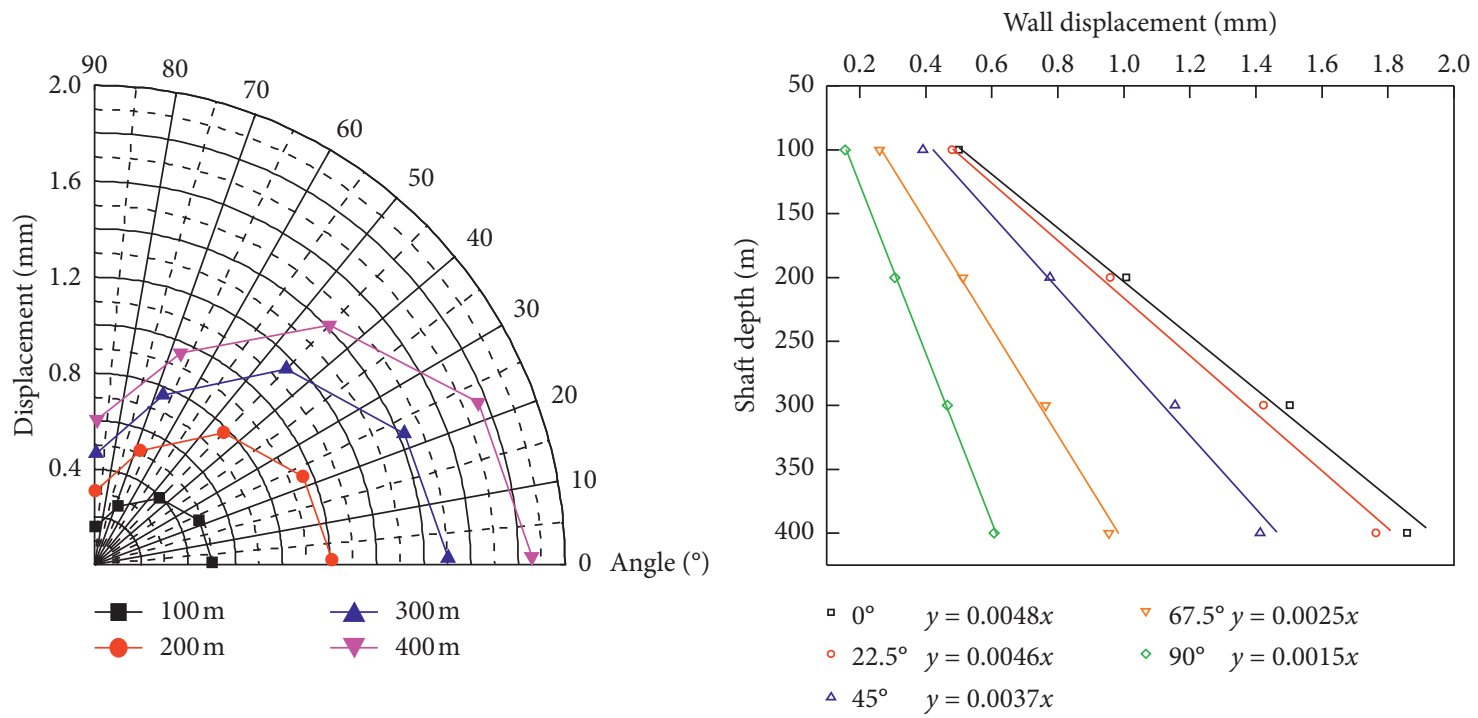

(a)
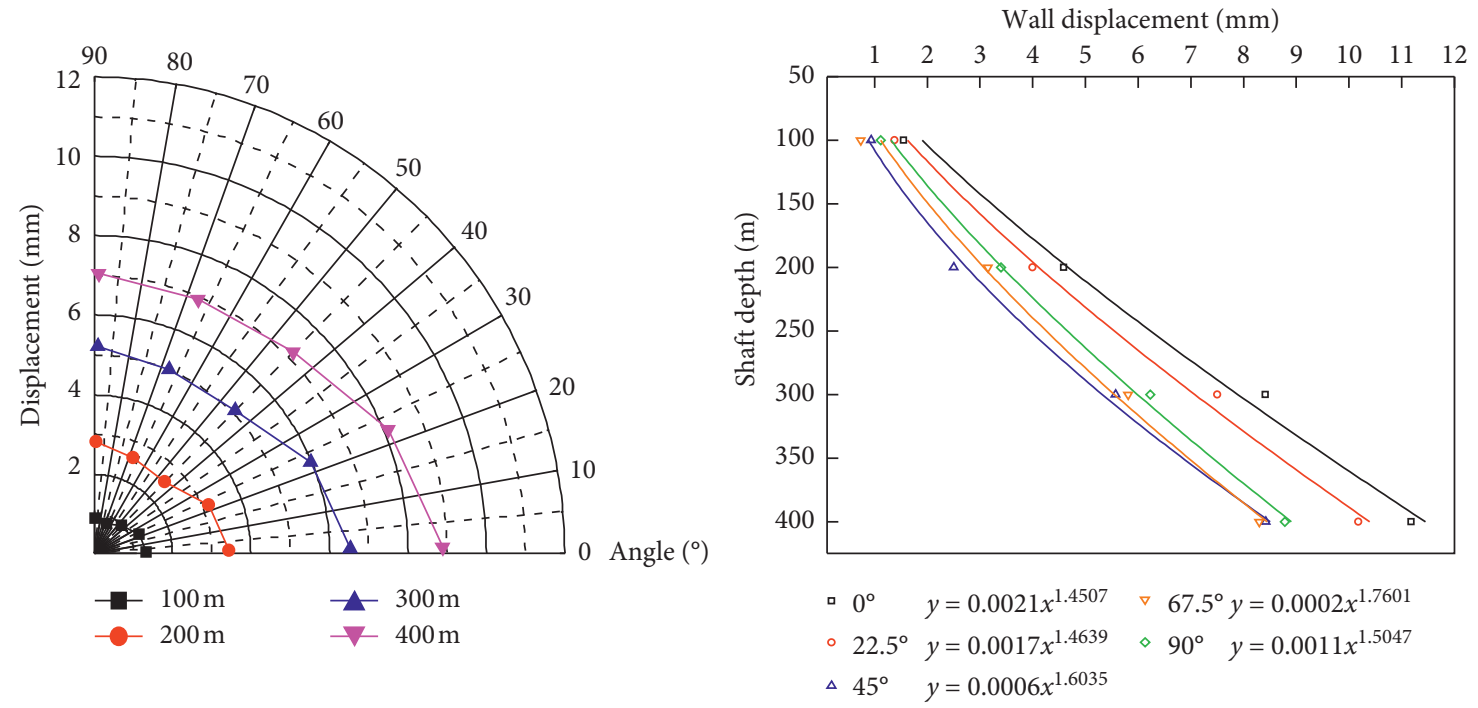

(b)

FIGURE 13: Radial displacement results of different model: (a) No BDZ; (b) BDZ (note the difference in wall displacement scales between the results presented in (a) and (b)).

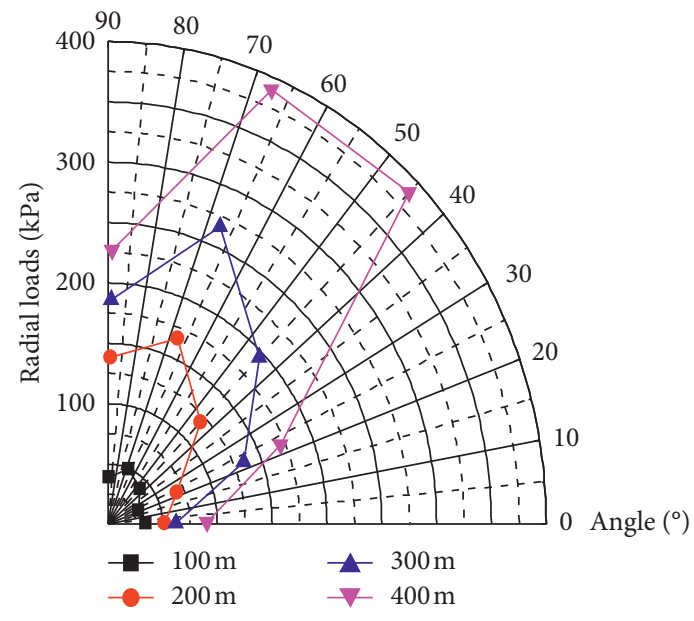

(a)

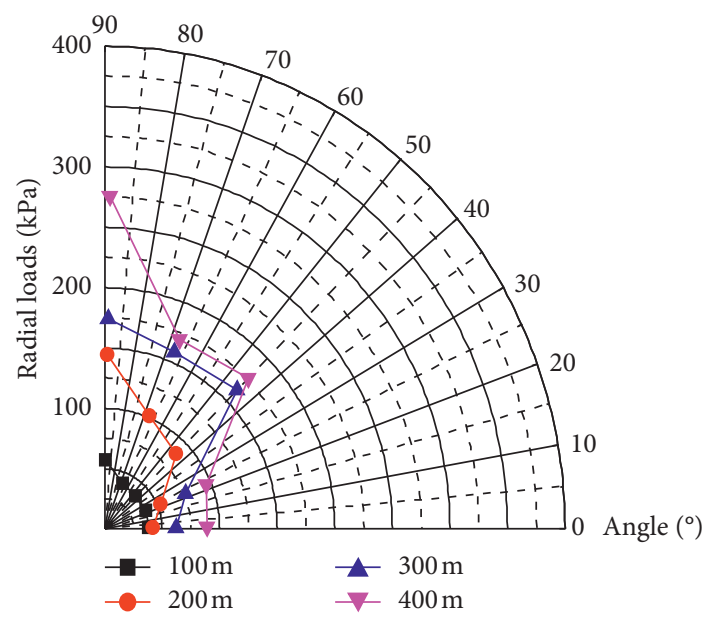

(b)

Figure 14: The radial loads calculated estimated using the CCCs: (a) No BDZ; (b) BDZ. 


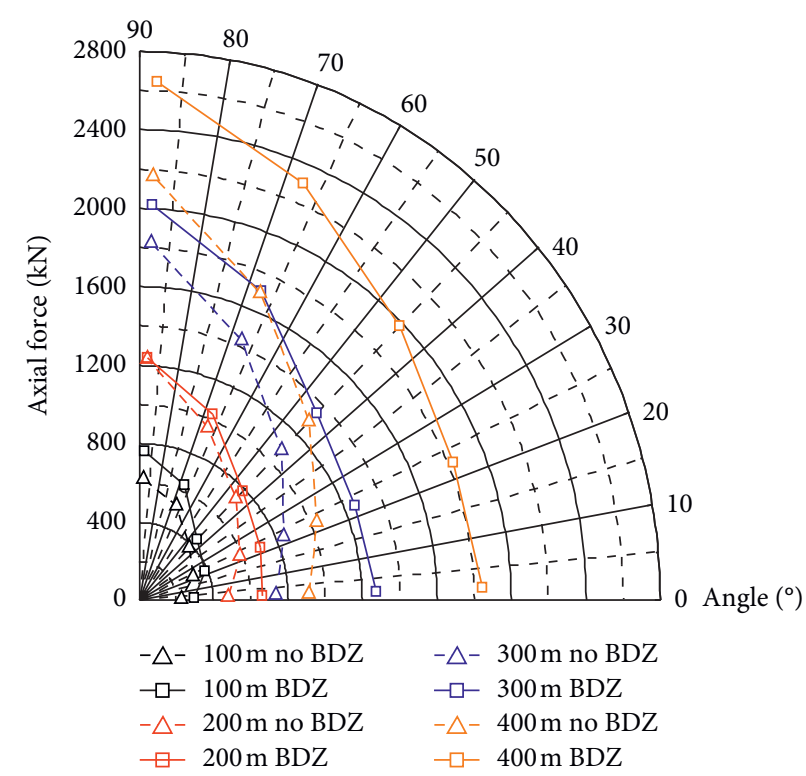

(a)

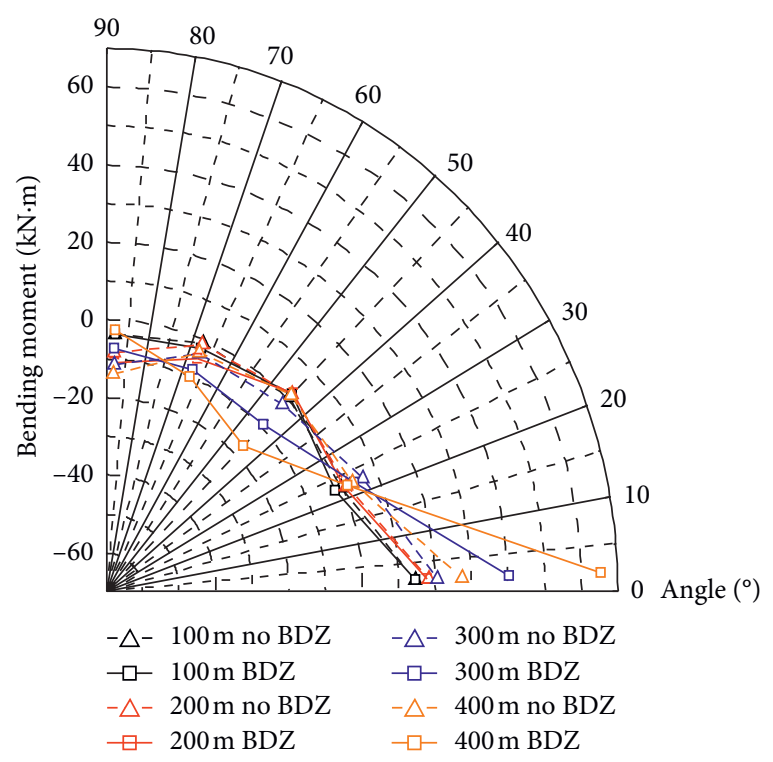

(b)

Figure 15: Modeled distributions of the (a) axial force in $\mathrm{kN}$ and (b) bending moment in $\mathrm{kN} \cdot \mathrm{m}$.

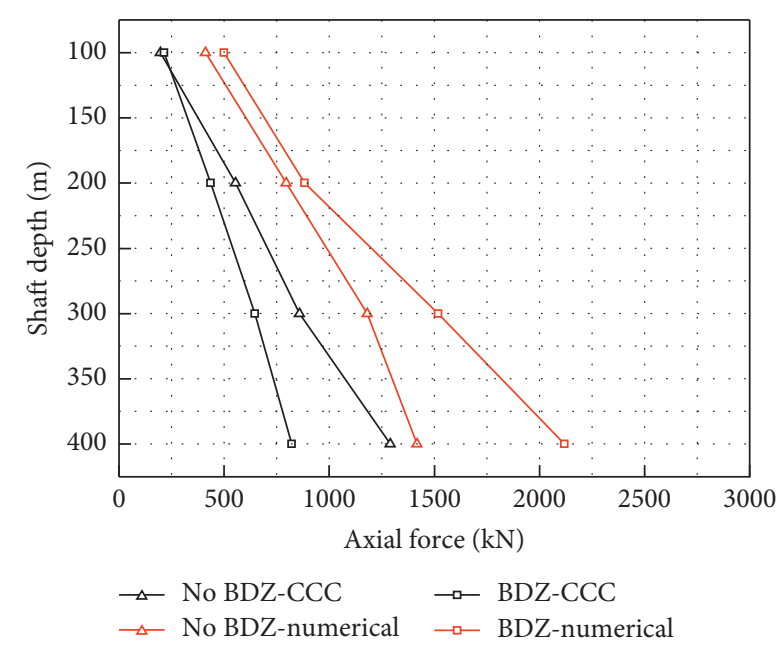

Figure 16: Maximum axial force versus depth as estimated using different analysis approaches.

5.3. Characteristics of Internal Force Distribution along Shaft. For tunnels, shafts, and other underground works constructed using the traditional method, the lining is often constructed in sections, and the loads acting on each segment of lining are assumed to be consistent [60]. However, for the shaft example presented, the lining is cast close to the shaft face, so the effect of surrounding rock displacement on the distribution of liner loads is significant. Some research shows that the displacement of surrounding rock around the excavation face changes rapidly with the advance of the excavation face [25]. The results mean that the excavation face acts as a constraint on the displacement of the shaft wall near the face. In general, for the short-step method, every advance distance contains two separate liner sections (the upper section and the lower section), where the upper section lining was installed after the advance in question, whereas the lower section was installed following the subsequent excavation advance. With this in mind, we would expect the upper sections to experience higher loading than the lower sections (where the lining was installed after a greater amount of ground deformation has already occurred).

Figure 19 shows the distribution of maximum axial force and maximum bending moment along shaft depth for four excavation advance distances; note that the BDZ was included in these models. As shown in Figure 19, the maximum axial force and bending moment increase as a function of effective depth in each section, but the distribution is discontinuous from the upper section to the lower section. The axial force at the lower end of the upper section is much larger than for the upper end of the lower section, and the difference increases as depth increases. These results confirm that the axial force is influenced by the stepped nature of the liner installation process.

The safety factor is a key parameter to assess the stability of the concrete lining, and it can be calculated as follows [60]:

$$
\begin{aligned}
& K=\frac{\varphi \alpha R_{\mathrm{a}} b h}{N}, \quad \text { for } e_{0} \leq 0.20 h, \\
& K=\varphi \frac{1.75 R_{\mathrm{l}} b h}{N\left(\left(6 e_{0} / h\right)-1\right)}, \text { for } e_{0}>0.20 h,
\end{aligned}
$$

here $K$ is the safety factor, $\varphi$ is the longitudinal bending coefficient, $\varphi=1$ for lining; $N$ is the axial force, $b$ is the width of the section, $h$ is the thickness of the section, $h=1 \mathrm{~m} ; R_{\mathrm{a}}$ is ultimate compressive strength, $R_{l}$ is ultimate tensile strength, $\varphi$ is the longitudinal bending coefficient, here $\varphi=1, e_{0}$ is the eccentricity; and $\alpha$ is the eccentricity influence coefficient, which can be calculated by 


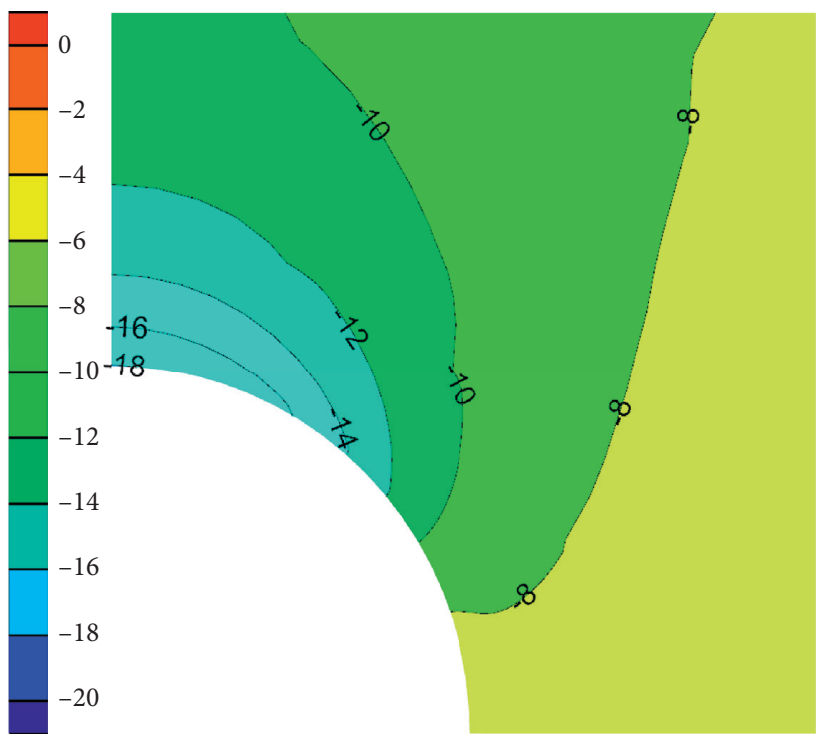

(a)

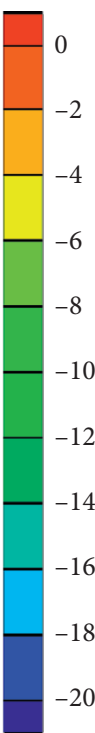

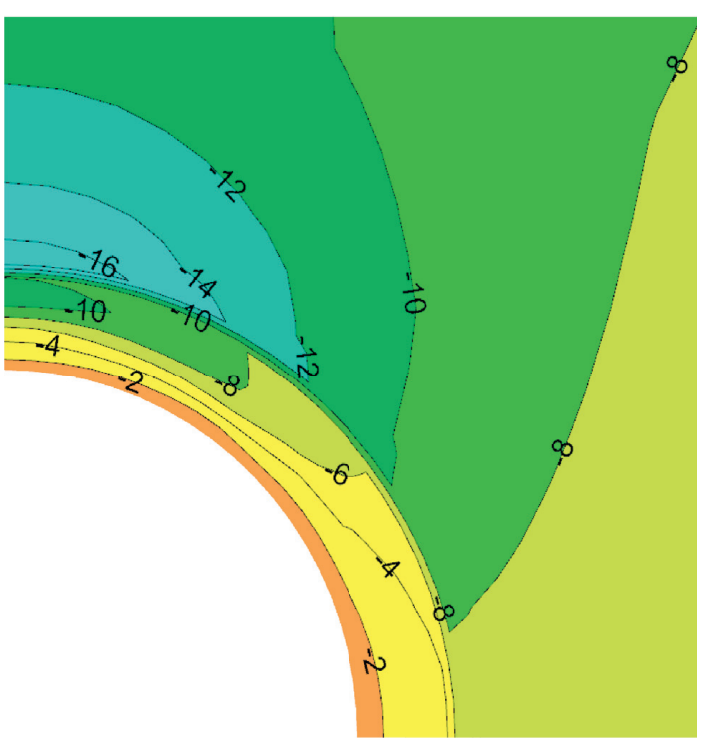

(b)

FIGURE 17: The distribution of shear stress of surrounding rock around shaft (depth $=300 \mathrm{~m}$, unit: MPa) (a) No damage zone included. (b) Damage zone included.
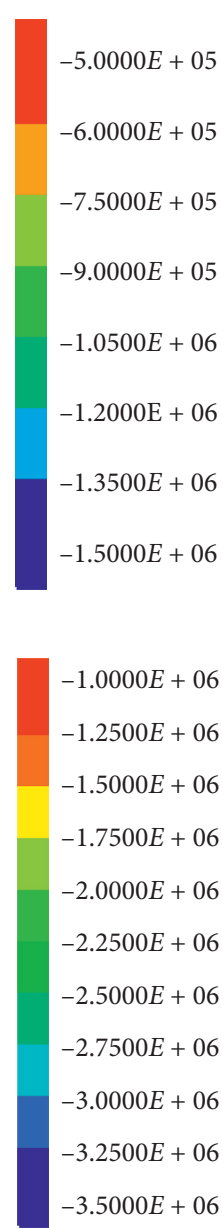

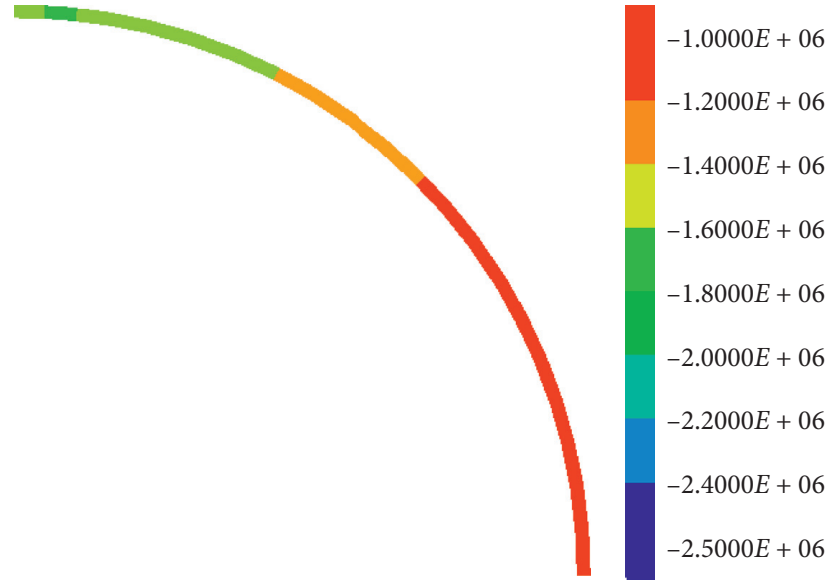

(a)

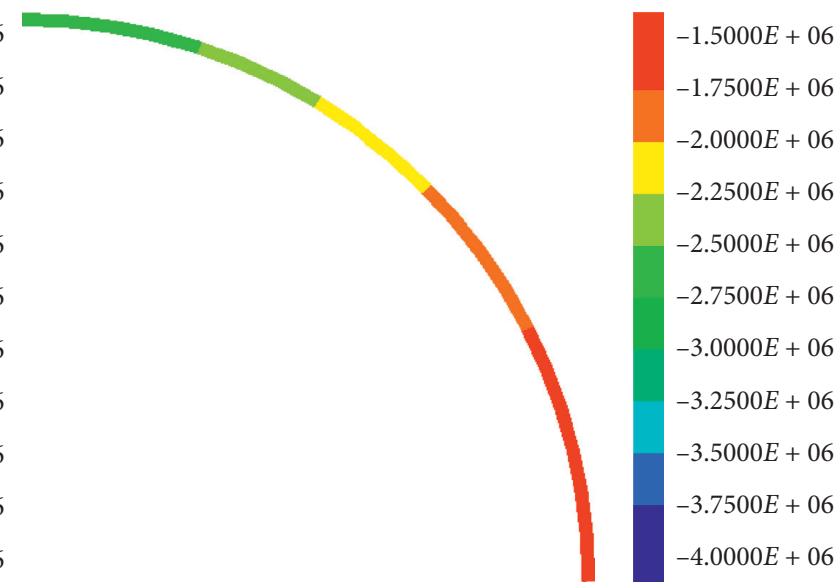

(c)

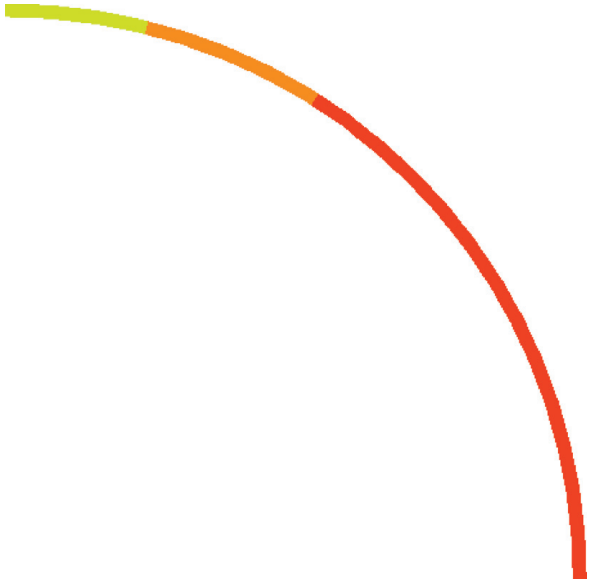

(b)

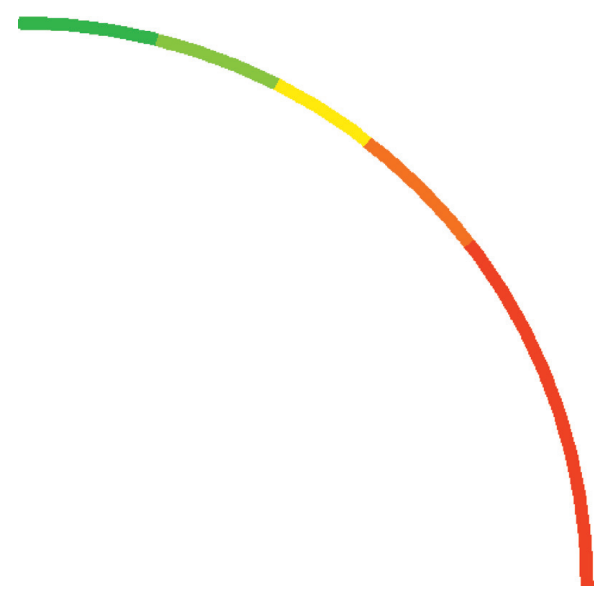

(d)

FIgURE 18: Continued. 


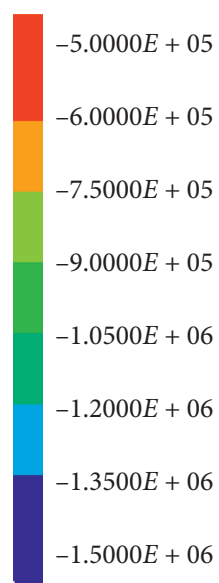

$-1.0000 E+06$
$-1.2500 E+06$
$-1.5000 E+06$
$-1.7500 E+06$
$-2.0000 E+06$
$-2.2500 E+06$
$-2.5000 E+06$
$-2.7500 E+06$
$-3.0000 E+06$
$-3.2500 E+06$
$-3.5000 E+06$

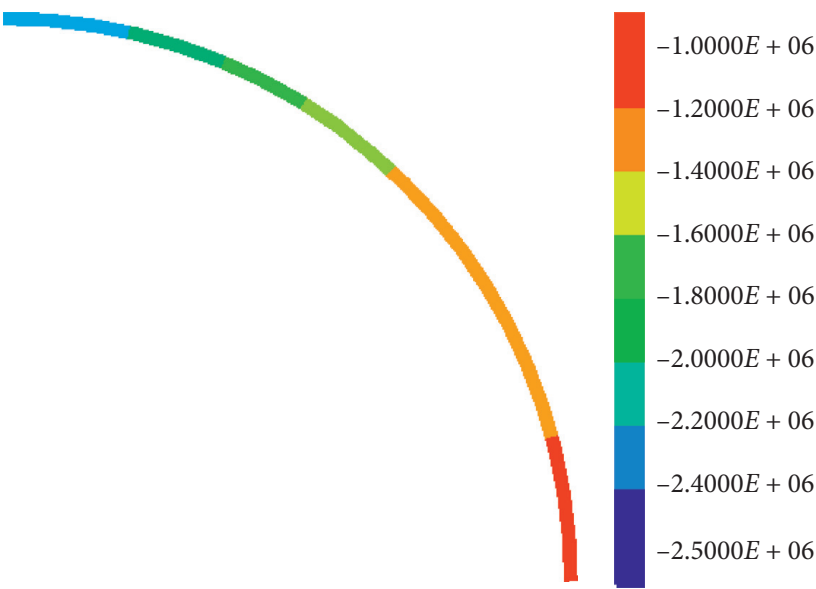

(e)

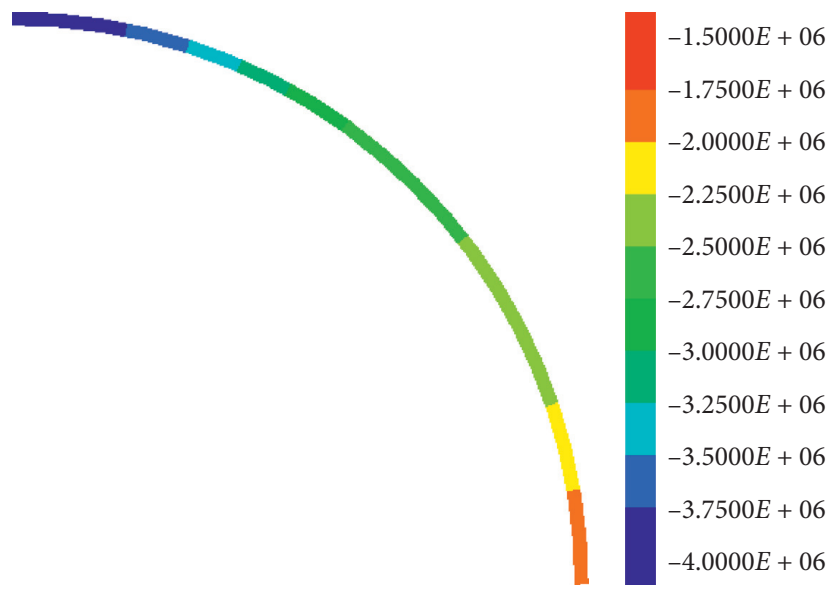

(g)

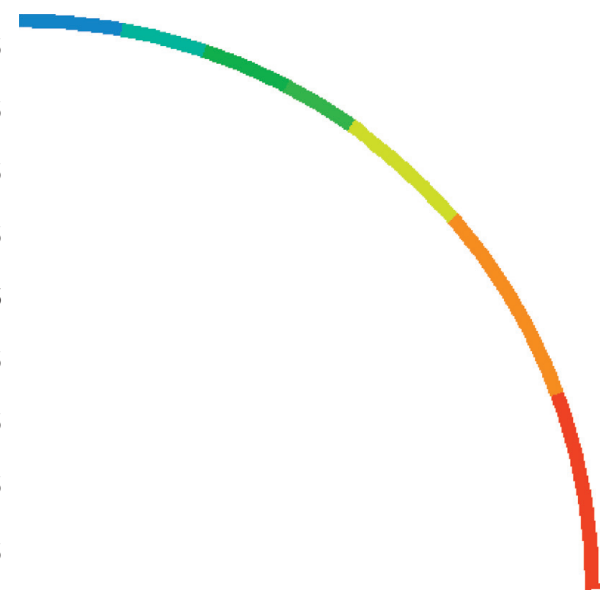

(f)

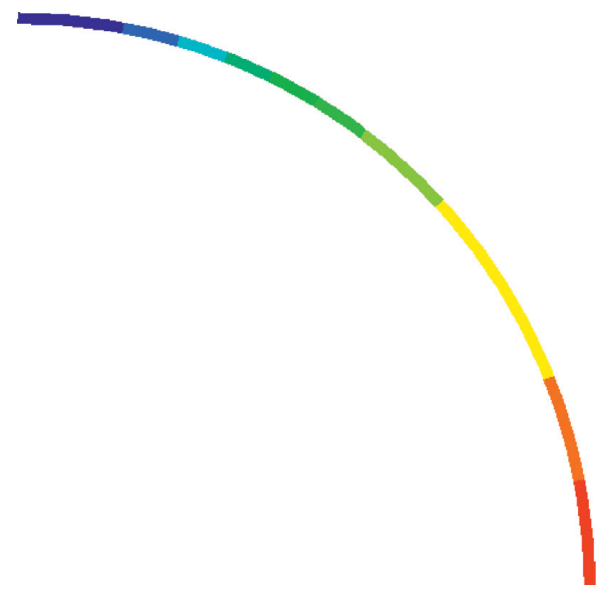

(h)

FIGURE 18: The contour map of maximum principal stress (a) (d) show the result of no BDZ, (e) (h) show the result of BDZ, corresponding to the section of $100 \mathrm{~m}, 200 \mathrm{~m}, 300 \mathrm{~m}$, and $400 \mathrm{~m}$, respectively (unit: $\mathrm{Pa}$ ).

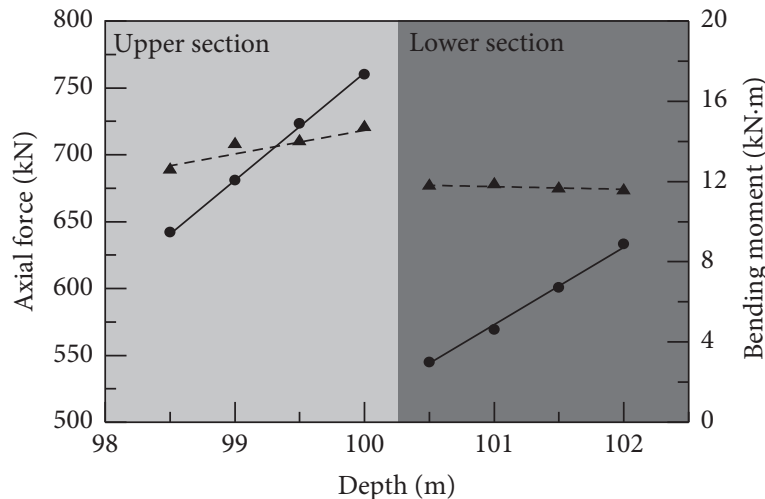

- Axial force

- Bending moment

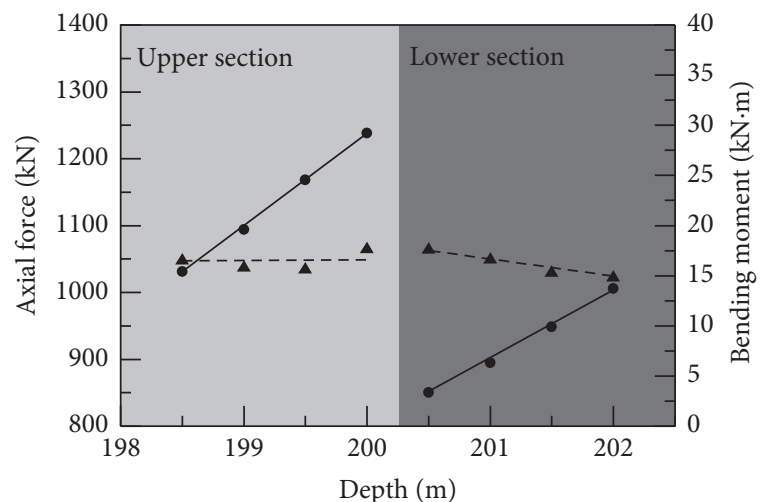

- Axial force

- Bending moment

(a)

Figure 19: Continued. 


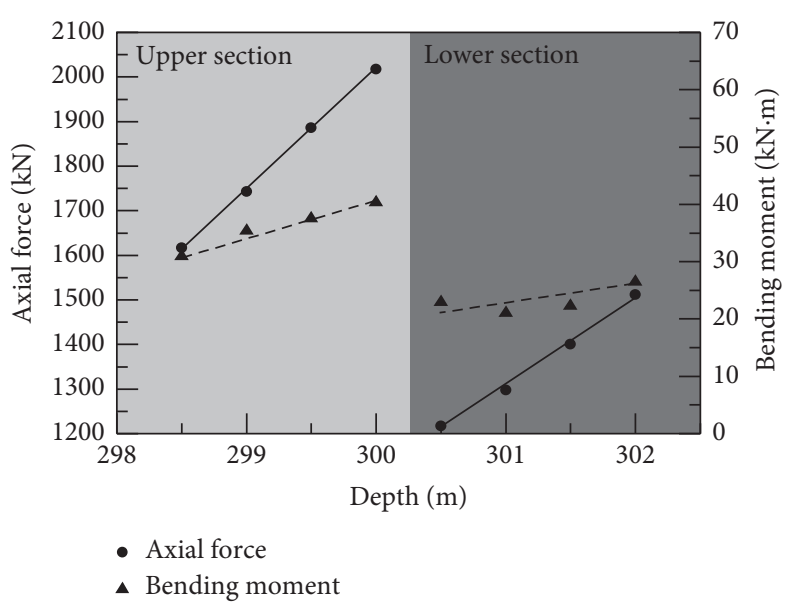

(c)

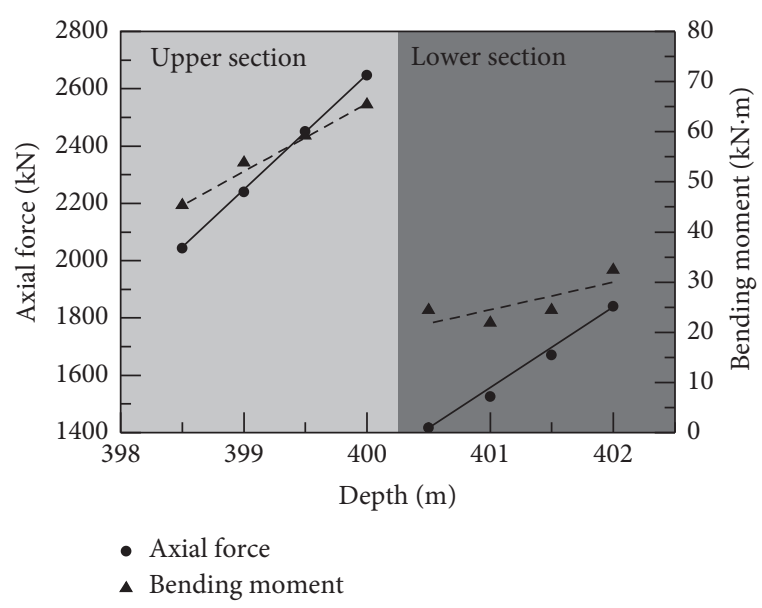

(d)

FIGURE 19: Numerically simulated maximum bending moment and axial force near different sections: (a) Section 1. (b) Section 2. (c) Section 3. (d) Section 4.

$$
\alpha=1.000+0.648\left(\frac{e_{0}}{h}\right)-12.569\left(\frac{e_{0}}{h}\right)^{2}+15.444\left(\frac{e_{0}}{h}\right)^{3} .
$$

Based on the results of numerical analysis, the safety factors of lining are calculated, as shown in Figure 20. The figure shows that the safety factor decreases with the increase of shaft depth; however, the minimum safety factor is 6.01, which is still bigger than the Critical safety factor (2.4). The results indicate that the $\mathrm{BDZ}$ increases the deformation of the surrounding rock and the magnitude of loads on the lining; the support pattern of the shaft lining is reliable. In addition, the results also indicate that the parameters of lining can be adjusted according to the shaft depth for the purpose of economic; for example, a thinner lining can be used to reduce construction costs in this project.

\section{Discussion and Recommendations}

The results suggest that for shafts sunk using a drill and blast method in hard rock, blast-induced damage exists near the shaft-rock boundary and can increase the displacement of the surrounding rock mass and the loads on the final lining relative to what might be predicted by conventional analyses that ignore the BDZ. Using a CCM approach, radial loads can be estimated, but the shear loads imparted to the lining from the ground in cases with anisotropic in situ stresses may be significant in terms of the overall lining behavior. Additionally, the evolution of lining properties over time, in particular, the concrete modulus, will affect the loads acting on the lining. Figure 21 illustrates the effect of how the Young's Modulus of concrete is modeled on the predicted axial force and bending moment. The results show that if the hardening process of concrete is not considered, the axial force could be underestimated by 27-63 percent and the bending moment could be underestimated by 3-64 percent (depending on the shaft depth considered).
In a general geomechanics context, the in situ measurement can ensure the safety during construction by giving warning of excess ground deformations and loads in support elements, and the method is applied widely in the field of engineering [61-63]. However, in this study, numerical analyses were conducted to study the impact of blast-induced damage on the rock load, and no in situ measurement was conducted for technical problems, and the in situ measurement should get addressed in future research.

\section{Conclusion}

Estimation of lining loads is critical to the proper design of any underground structure, and shafts are no exception. Although several methods have been proposed to determine the lining loads for underground structures, many of them ignore important influences of the construction method and processes, such as blasting-induced damage or the timedependent evolution of lining stiffness after installation. In this study, field tests and numerical analyses were conducted to study these issues. Based on these analyses, the following conclusions can be made:

(i) In the project in this study, the average P-wave velocity of the BDZ was found to be approximately half that of the undamaged rock mass, and the thickness of the BDZ was found to be in the range of 1.1-1.4 $\mathrm{m}$. The existence of the BDZ increases the displacement of the surrounding rock and hence the magnitude of ground loads on the lining.

(ii) For excavations in anisotropic stress field, the ground applies both radial and shear loads to the lining at the lining-rock boundary. Although the CCM seems to be sufficient to calculate the radial loads, the overall lining loads could be underestimated by this method due to its inability to account for shear loading. 


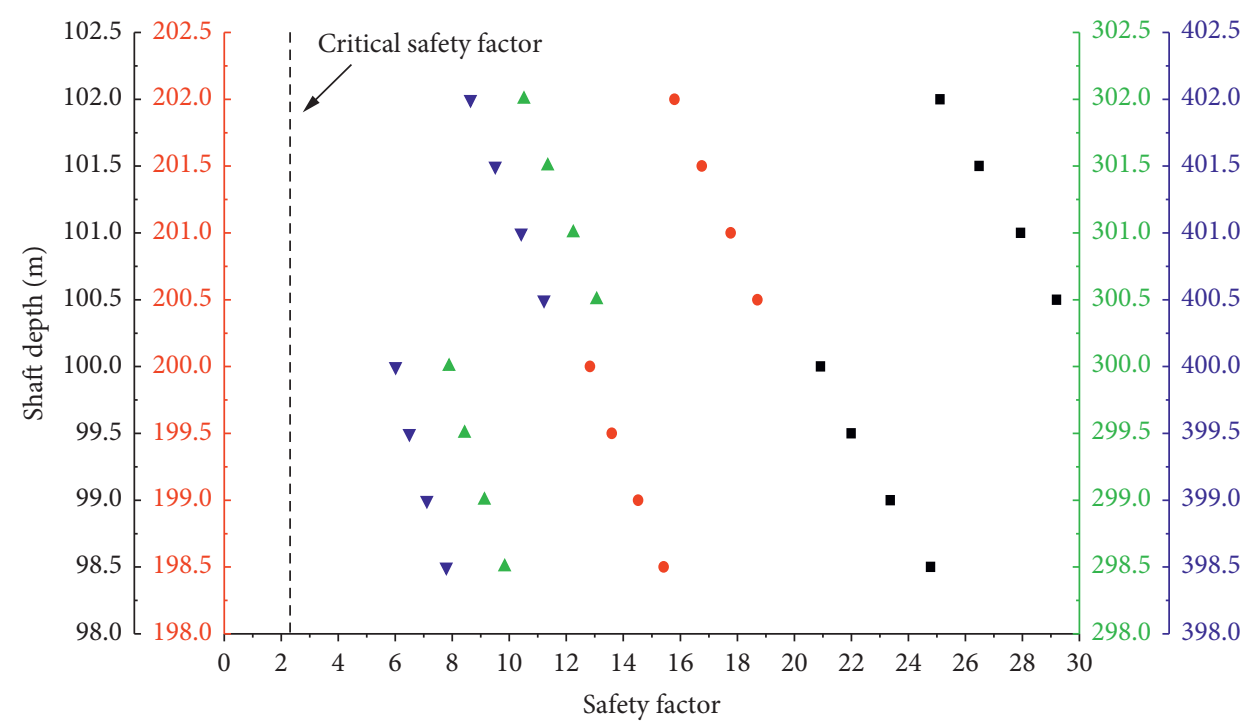

FIgURE 20: The safety factors of lining.

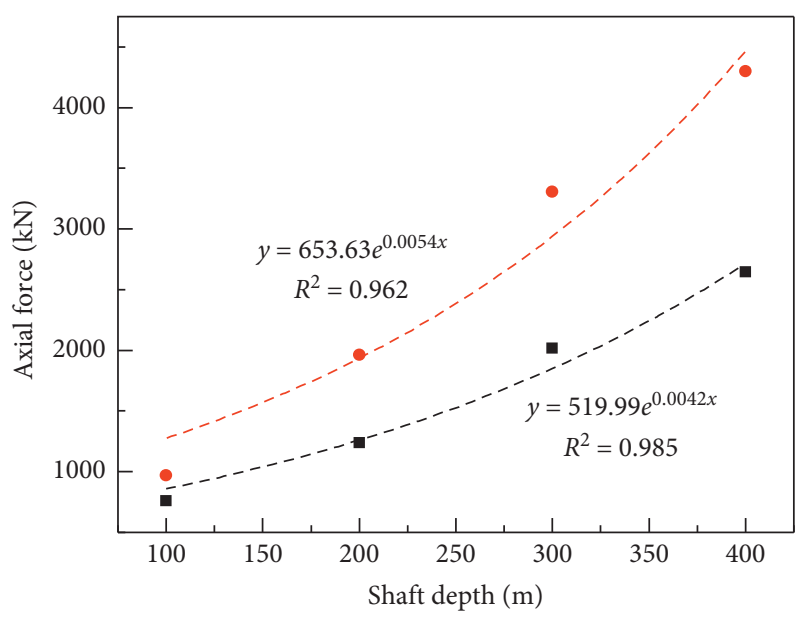

- Variable modulus

- Constant modulus

(a)

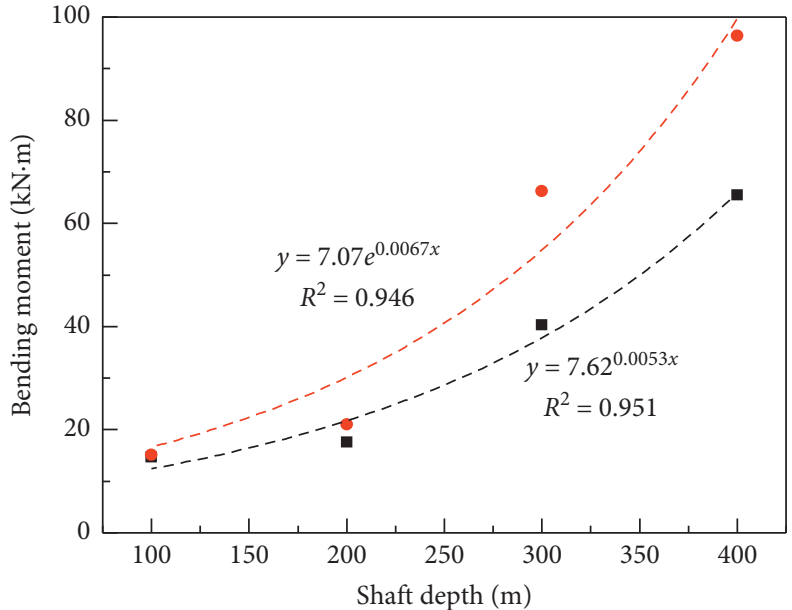

- Variable modulus

- Constant modulus

FiguRE 21: Maximum axial force and maximum bending moment as estimated using different models for liner modulus: (a) axial force in $\mathrm{kN}$ and (b) bending moment in $\mathrm{kN} \cdot \mathrm{m}$.

(iii) For shafts excavated by the short-step method, the loads acting on the lining are discontinuous, and there could be a notable difference between the load acting on adjacent lining segments.

\section{Data Availability}

The data used to support the findings of this study are available from the corresponding author upon request.

\section{Conflicts of Interest}

The authors declare that they have no conflicts of interest.

\section{Acknowledgments}

This research was funded by the National Key Research and Development Program of China (NO. 2016YFC0802205), the National Natural Science Foundation of China (NO. 51578460) and the Key Research and Development Program of the Sichuan Science and Technology Plan (NO. 2017SZ0043).

\section{References}

[1] H. Y. Cong, X. S. Wang, P. Zhu, T. H. Jiang, and X. J. Shi, "Improvement in smoke extraction efficiency by natural ventilation through a board-coupled shaft during tunnel fires," Applied Thermal Engineering, vol. 118, pp. 127-137, 2017. 
[2] C. Liu, M. Zhong, C. Shi, P. Zhang, and X. Tian, "Temperature profile of fire-induced smoke in node area of a full-scale mine shaft tunnel under natural ventilation," Applied Thermal Engineering, vol. 110, pp. 382-389, 2017.

[3] G. Wu, W. Chen, H. Bian, and J. Yuan, "Structure optimisation of a diaphragm wall with special modelling methods in a large-scale circular ventilating shaft considering shield crossing," Tunnelling and Underground Space Technology, vol. 65, pp. 35-41, 2017.

[4] Y. Fang, J. Fan, B. Kenneally, and M. Mooney, "Air flow behavior and gas dispersion in the recirculation ventilation system of a twin-tunnel construction," Tunnelling and Underground Space Technology, vol. 58, pp. 30-39, 2016.

[5] X. P. Zhang, M. Lu, D. Mao, Z. Zhao, and L. Hao, "Design and construction of shaft for rock caverns in Singapore," Geomechanics and Engineering, vol. 13, no. 1, pp. 173-194, 2017.

[6] T. G. S. Dias, M. M. Farias, and A. P. Assis, "Large diameter shafts for underground infrastructure," Tunnelling and Underground Space Technology, vol. 45, pp. 181-189, 2015.

[7] K. Terzaghi, Theoretical Soil Mechanics, John Wiley \& Sons, New York, NY, USA, 1943.

[8] B. Bros, "The influence of model retaining wall displacements on active and passive earth pressure in sand," in Proceedings of the 5th European Conference on Soil Mechanics and Foundation Engineering, vol. 1, pp. 241-249, Madrid, Spain, 1972.

[9] M. A. Sherif, Y. S. Fang, and R. I. Sherif, "KA and KO behind rotating and non-yielding walls," Journal of Geotechnical Engineering, vol. 110, no. 1, pp. 41-56, 1984.

[10] E. G. Prater, "An examination of some theories of earth pressure on shaft linings," Canadian Geotechnical Journal, vol. 14, no. 1, pp. 91-106, 1977.

[11] F. Q. Liu, J. H. Wang, and L. L. Zhang, “Axi-symmetric active earth pressure obtained by the slip line method with a general tangential stress coefficient," Comput Geotech, vol. 36, no. 1-2, pp. 352-358, 2009.

[12] T. Fujii, T. Hagiwara, K. Ueno, and A. Taguchi, "Experiment and analysis of earth pressure on an axisymmetric shaft in sand," in Proceedings of the International Conference on Centrifuge, pp. 791-796, Singapore, 1994.

[13] M. Herten and M. Pulsfort, "Determination of spatial earth pressure on circular shaft constructions," Granular Matter, vol. 2, no. 1, pp. 1-7, 1999.

[14] B. Chun and Y. Shin, "Active earth pressure acting on the cylindrical retaining wall of a shaft," South Korea Ground Environmental Engineering Journal, vol. 7, no. 4, pp. 15-24, 2006.

[15] V. D. H. Tran, M. A. Meguid, and L. E. Chouinard, "Discrete element and experimental investigations of the earth pressure distribution on cylindrical shafts," International Journal of Geomechanics, vol. 14, no. 1, pp. 80-91, 2014.

[16] K.-Y. Kim, D.-S. Lee, J. Cho, S.-S. Jeong, and S. Lee, “The effect of arching pressure on a vertical circular shaft," Tunnelling and Underground Space Technology, vol. 37, pp. 10-21, 2013.

[17] J. Cho, H. Lim, S. Jeong, and K. Kim, "Analysis of lateral earth pressure on a vertical circular shaft considering the $3 \mathrm{D}$ arching effect," Tunnelling and Underground Space Technology, vol. 48, pp. 11-19, 2015.

[18] T. Tobar and M. A. Meguid, "Comparative evaluation of methods to determine the earth pressure distribution on cylindrical shafts: a review," Tunnelling and Underground Space Technology, vol. 25, no. 2, pp. 188-197, 2010.

[19] T. Kitagawa, T. Kumeta, T. Ichizyo, S. Soga, M. Sato, and M. Yasukawa, "Application of Convergence Confinement Analysis to the study of preceding displacement of a squeezing rock tunnel," Rock Mechanics and Rock Engineering, vol. 24, no. 1, pp. 31-51, 1991.

[20] C. Carranza-Torres and C. Fairhurst, "Application of the convergence-confinement method of tunnel design to rock masses that satisfy the Hoek-Brown failure criterion," Tunnelling and Underground Space Technology, vol. 15, no. 2, pp. 187-213, 2000.

[21] P. P. Oreste, "Analysis of structural interaction in tunnels using the covergence-confinement approach," Tunnelling and Underground Space Technology, vol. 18, no. 4, pp. 347-363, 2003.

[22] N. Vlachopoulos and M. S. Diederichs, "Improved longitudinal displacement profiles for convergence confinement analysis of deep tunnels," Rock Mechanics and Rock Engineering, vol. 42, no. 2, pp. 131-146, 2009.

[23] Q. Yan, S. C. Li, C. Xie, and Y. Li, "Analytical solution for bolted tunnels in expansive loess using the convergenceconfinement method," International Journal of Geomechanics, vol. 18, no. 1, Article ID 04017124, 2018.

[24] R. C. K. Wong and P. K. Kaiser, "Design and performance evaluation of vertical shafts: rational shaft design method and verification of design method," Canadian Geotechnical Journal, vol. 25, no. 2, pp. 320-337, 1988.

[25] G. Spagnoli, P. Oreste, and L. Lo Bianco, "New equations for estimating radial loads on deep shaft linings in weak rocks," International Journal of Geomechanics, vol. 16, no. 6, Article ID 06016006, 2016.

[26] G. Spagnoli, P. Oreste, and L. Lo Bianco, "Estimation of shaft radial displacement beyond the excavation bottom before installation of permanent lining in nondilatant weak rocks with a novel formulation," International Journal of Geomechanics, vol. 17, no. 9, Article ID 04017051, 2017.

[27] G. Walton and M. S. Diederichs, "A mine shaft case study on the accurate prediction of yield and displacements in stressed ground using lab-derived material properties," Tunnelling and Underground Space Technology, vol. 49, pp. 98-113, 2015.

[28] B. Van de Steen, A. Vervoort, J. A. L. Napier, and R. J. Durrheim, "Implementation of a flaw model to the fracturing around a vertical shaft," Rock Mechanics and Rock Engineering, vol. 36, no. 2, pp. 143-161, 2003.

[29] H. R. Renani, C. D. Martin, and R. Hudson, "Back analysis of rock mass displacements around a deep shaft using two- and three-dimensional continuum modeling," Rock Mechanics and Rock Engineering, vol. 49, no. 4, pp. 1313-1327, 2016.

[30] P. Yan, W.-b. Lu, M. Chen, Y.-g. Hu, C.-b. Zhou, and $\mathrm{X} .-\mathrm{x} . \mathrm{Wu}$, "Contributions of in-situ stress transient redistribution to blasting excavation damage zone of deep tunnels," Rock Mechanics and Rock Engineering, vol. 48, no. 2, pp. 715-726, 2015.

[31] L. Xu, H. Schreyer, and D. Sulsky, "Blast-induced rock fracture near a tunnel," International Journal for Numerical and Analytical Methods in Geomechanics, vol. 39, no. 1, pp. 23-50, 2015.

[32] M. Chen, W. B. Lu, P. Yan, and Y. G. Hu, "Blasting excavation induced damage of surrounding rock masses in deep-buried tunnels," KSCE Journal of Civil Engineering, vol. 20, no. 2, pp. 933-942, 2016.

[33] L. X. Xie, W. B. Lu, Q. B. Zhang, Q. H. Jiang, G. H. Wang, and J. Zhao, "Damage evolution mechanisms of rock in deep tunnels induced by cut blasting," Tunnelling and Underground Space Technology, vol. 58, pp. 257-270, 2016.

[34] J. H. Yang, Q. H. Jiang, Q. B. Zhang, and J. Zhao, "Dynamic stress adjustment and rock damage during blasting excavation 
in a deep-buried circular tunnel," Tunnelling and Underground Space Technology, vol. 71, pp. 591-604, 2018.

[35] O. Yilmaz and T. Unlu, "Three dimensional numerical rock damage analysis under blasting load," Tunnelling and Underground Space Technology, vol. 38, pp. 266-278, 2013.

[36] J. Yang, W. Lu, Y. Hu, M. Chen, and P. Yan, "Numerical simulation of rock mass damage evolution during deepburied tunnel excavation by drill and blast," Rock Mechanics and Rock Engineering, vol. 48, no. 5, pp. 2045-2059, 2015.

[37] H. K. Verma, N. K. Samadhiya, M. Singh, R. K. Goel, and P. K. Singh, "Blast induced rock mass damage around tunnels," Tunnelling and Underground Space Technology, vol. 71, pp. 149-158, 2018.

[38] H. Öztürk and E. Ünal, "Estimation of lining thickness around circular shafts," in Proceedings of the 17th International Mining Congress and Exhibition of Turkey-IMCET2001, pp. 437-444, Ankara, Turkey, June 2001.

[39] W. A. Peck and M. F. Lee, "Application of the Q-system to Australian underground metal mines," in Proceedings of the International Workshop on Rock Mass Classification in Underground Mining, C. Mark, R. Pakalnis, and R. J. Tuchman, Eds., pp. 129-140pp. 129-, Vancouver, Canada, May 2007.

[40] G. Bruneau, M. R. Hudyma, J. Hadjigeorgiou, and Y. Potvin, "Influence of faulting on a mine shaft-a case study: part IInumerical modelling," International Journal of Rock Mechanics and Mining Sciences, vol. 40, no. 1, pp. 113-125, 2003.

[41] H. Sanada, T. Sato, Y. Horiuchi et al., "Excavation cycle times recorded during sinking of a deep shaft in crystalline rock-a case example at ventilation shaft of Mizunami URL, Japan," Tunnelling and Underground Space Technology, vol. 50, pp. 68-78, 2015.

[42] J. Lai, K. Wang, J. Qiu, F. Niu, J. Wang, and J. Chen, "Vibration response characteristics of the cross tunnel structure," Shock and Vibration, vol. 2016, Article ID 9524206, 16 pages, 2016.

[43] J. Lai, H. Fan, B. Liu, and T. Liu, "Analysis of seismic response of shallow large section multi-arch tunnel," Procedia Engineering, vol. 15, pp. 5473-5477, 2011.

[44] L. Malmgren, D. Saiang, J. Töyrä, and A. Bodare, "The excavation disturbed zone (EDZ) at Kiirunavaara mine, Sweden-by seismic measurements," Journal of Applied Geophysics, vol. 61, no. 1, pp. 1-15, 2007.

[45] T. Sato, T. Kikuchi, and K. Sugihara, "In-situ experiments on an excavation disturbed zone induced by mechanical excavation in Neogene sedimentary rock at Tono mine, central Japan," Engineering Geology, vol. 56, no. 1-2, pp. 97-108, 2000.

[46] T. Liu, J. Li, H. Li, X. Li, Y. Zheng, and H. Liu, "Experimental study of s-wave propagation through a filled rock joint," Rock Mechanics and Rock Engineering, vol. 35, no. 2, pp. 113-121, 2017.

[47] Y. M. Alshkane, A. M. Marshall, and L. R. Stace, "Prediction of strength and deformability of an interlocked blocky rock mass using udec," Journal of Rock Mechanics and Geotechnical Engineering, vol. 9, no. 3, pp. 531-542, 2017.

[48] Z. T. Bieniawski, "Engineering classification of jointed rock masses," Trans S African Inst Civ Engrs, vol. 15, no. 12, pp. 335-344, 1973.

[49] N. Barton, R. Lien, and J. Lunde, "Engineering classification of rock masses for the design of tunnel support," Rock Mechanics Felsmechanik Mecanique des Roches, vol. 6, no. 4, pp. 189-236, 1974.

[50] E. Hoek and E. T. Brown, "Practical estimates of rock mass strength," International Journal of Rock Mechanics and Mining Sciences, vol. 34, no. 8, pp. 1165-1186, 1997.
[51] N. Barton, "Some new Q-value correlations to assist in site characterisation and tunnel design," International Journal of Rock Mechanics and Mining Sciences, vol. 39, no. 2, pp. 185-216, 2002.

[52] E. Hoke, C. Carranza-Torres, and B. Corkum, "Hoke-Brown criterion-2002 edition," in Proceedings of the .NARMS-TAC Conference, vol. 1, pp. 267-273, Toronto, Canada, 2002.

[53] V. Marinos, P. Marinos, and E. Hoek, "The geological strength index: applications and limitations," Bulletin of Engineering Geology and the Environment, vol. 64, no. 1, pp. 55-65, 2005.

[54] M. Cai, P. K. Kaiser, Y. Tasaka, and M. Minami, "Determination of residual strength parameters of jointed rock masses using the GSI system," International Journal of Rock Mechanics and Mining Sciences, vol. 44, no. 2, pp. 247-265, 2007.

[55] Y. Shen, G. Xu, Lu Zhang, and K. Zhu, "Research on characteristics of rock deformation caused by excavation disturbance based on Hoke-Brown criterion," Chinses Journal of Rock Mechanics and Engineering, vol. 29, no. 7, pp. 1355-1362, 2010.

[56] E. Hoek and E. T. Brown, "The Hoek-Brown failure criterion a 1988 update," in Proceedings of the 15th Canadian Rock Mechanics Symposium, pp. 31-38, Civil Engineering University of Toronto, Toronto, Canada, 1988.

[57] C. Zhao, A. Alimardani Lavasan, T. Barciaga, C. Kämper, P. Mark, and T. Schanz, "Prediction of tunnel lining forces and deformations using analytical and numerical solutions," Tunnelling and Underground Space Technology, vol. 64, pp. 164-176, 2017.

[58] G. Walton, E. Kim, S. Sinha, G. Sturgis, and D. Berberick, "Investigation of shaft stability and anisotropic deformation in a deep shaft in Idaho, United States," International Journal of Rock Mechanics and Mining Sciences, vol. 105, pp. 160-171, 2018.

[59] M. M. Wang, "Experimental study on mechanical behavior of C40 concrete at early age," Beijing Jiaotong University, Beijing, China, Doctoral dissertation, 2014.

[60] Ministry of Transport of the People's Republic of China, Code for Design of Road Tunnel (JTG D70-2004), China Communications Press, Beijing, China, 2004.

[61] B. H. G. Brady and E. T. Brown, Rock Mechanics for Underground Mining, George Allen \& Unwin, London, UK, 1985.

[62] L. Li, S. Li, and Z. Qingsong, "In-situ testing study on shallowburied large-span tunnel," Chinese Journal of Rock Mechanics and Engineering, vol. 26, no. 1, pp. 3565-3571, 2007.

[63] J. X. Lai, F. Y. Niu, H. B. Fan, J. L. Qiu, and K. Y. Wang, "Field test of mechanical characteristics of three-layer support structure of shallow loess tunnel," Rock and Soil Mechanics, vol. 36, no. 6, pp. 1769-1775, 2015. 